Florida International University

FIU Digital Commons

FIU Electronic Theses and Dissertations

University Graduate School

$4-1982$

\title{
The analysis of the resort timesharing industry in order to determine the industry's familiarity with timesharing and the industry's conception of the present and future effects of timesharing
}

Lisa S. Aufzien

Florida International University

Julie Krimmer

Florida International University

DOI: $10.25148 /$ etd.FI14032370

Follow this and additional works at: https://digitalcommons.fiu.edu/etd

Part of the Hospitality Administration and Management Commons

\section{Recommended Citation}

Aufzien, Lisa S. and Krimmer, Julie, "The analysis of the resort timesharing industry in order to determine the industry's familiarity with timesharing and the industry's conception of the present and future effects of timesharing" (1982). FIU Electronic Theses and Dissertations. 1336.

https://digitalcommons.fiu.edu/etd/1336

This work is brought to you for free and open access by the University Graduate School at FIU Digital Commons. It has been accepted for inclusion in FIU Electronic Theses and Dissertations by an authorized administrator of FIU Digital Commons. For more information, please contact dcc@fiu.edu. 
The Analysis of the Resort Timesharing Industry in order to Determine the Industry's Familiarity with Timesharing and the Industry's conception of the Present and Future Effects of Timesharing

by

\author{
Lisa s. Aufzien \\ and \\ Julie Krimmer
}

a hospitality project submitted in partial fulfillment of the requirements for the degree of

Master of Science

in

Hotel and Food Service Management

at

Florida International University

committee in charge:

Professor D. Greenaway - Chairperson

Professor C. Ilvento

April 1982 
The Analysis of the Resort Timesharing Industry in order to Determine the Industry's Familiarity with Timesharing and the Industry's Conception of the Present and Future Effects of Timesharing

\title{
by
}

\author{
Lisa S. Aufzien \\ and \\ Julie Krimmer
}

a hospitality project submitted in partial fulfillment of the requirements for the degree of

\author{
Master of Science \\ in
}

Hotel and Food Service Administration

at

Florida International University

1982 
To Professors D. Greenaway and C. Ilvento,

This hospitality project is being referred to you for judgement upon its substantial merit.

This hospitality project of Lisa S. Aufzien and Julie Krimmer is approved.

Date of Examination: April 1982 
Preliminaries

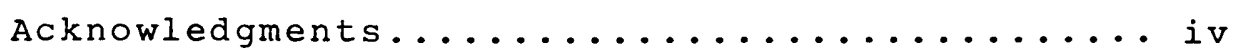

Abstract.......................... v v

I. The Problem and its setting............ I

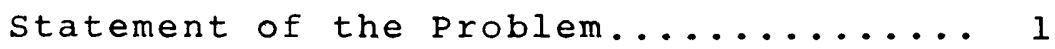

Statement of the subproblems........... 1

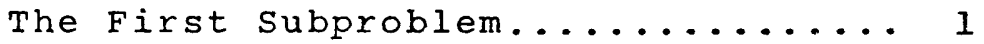

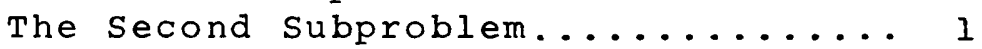

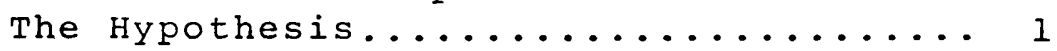

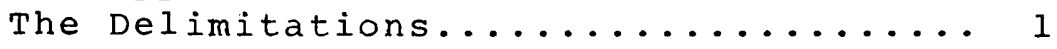

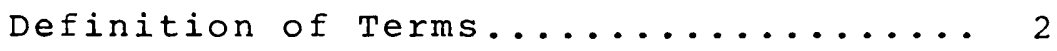

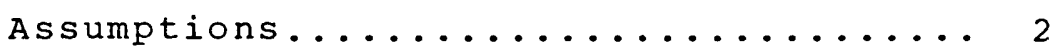

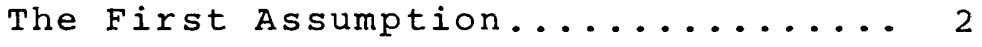

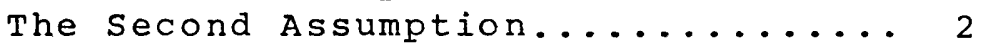

The Importance of the study........... 2

Footnotes...................... 4

II. The Review of the Related Literature..... 5

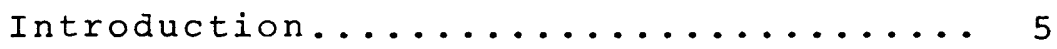

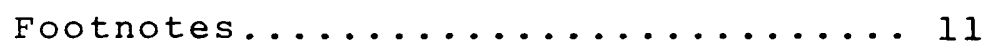

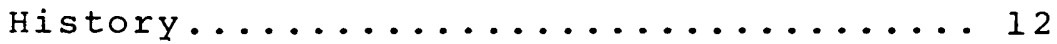

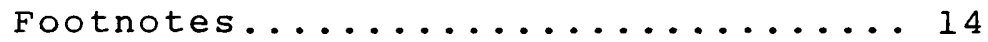

The Different Forms of Timesharing.... 15

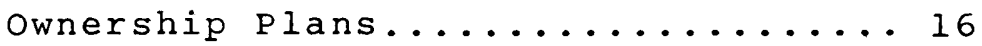

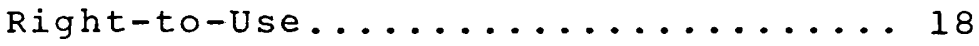

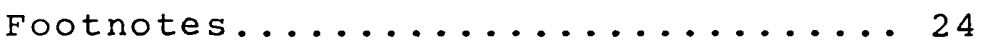

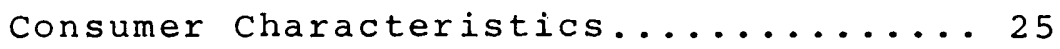

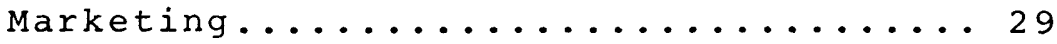

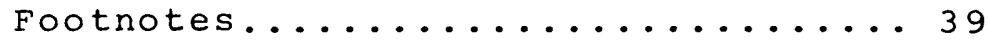

Timeshare Characteristics.......... 40

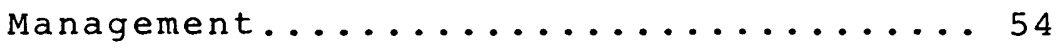

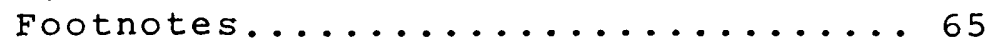

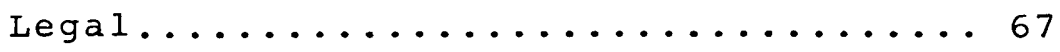

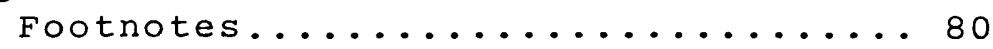

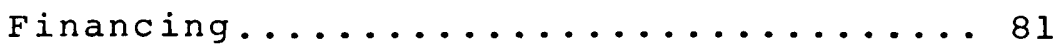

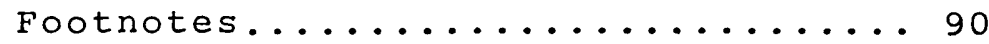

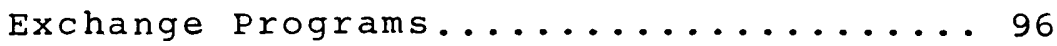

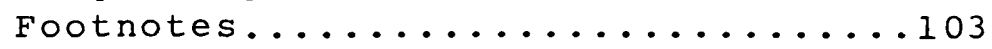

Advantages of Resort Timesharing......131

Limitations of Resort Timesharing.....133

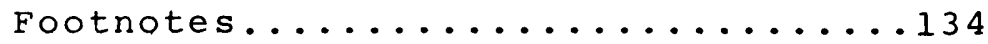

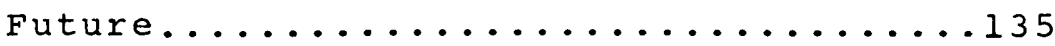

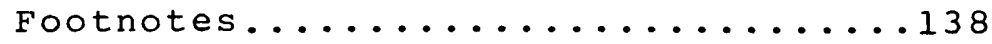


Table of Contents (Continued)

III. The Data and the Treatment of the Data...139

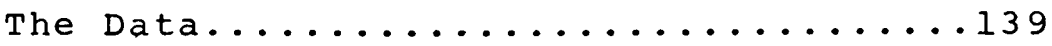

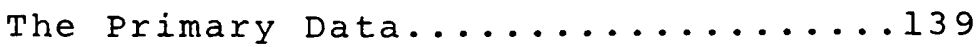

The Secondary Data 139

The Criteria Governing the admissibil-

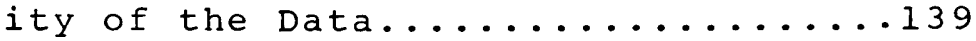

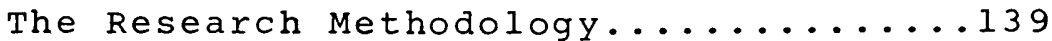

The Specific Treatment of Each Problem.141

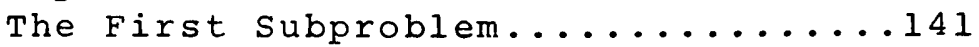

The second subproblem.............142

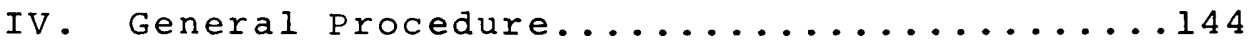

Determining the Design of the Sample...144

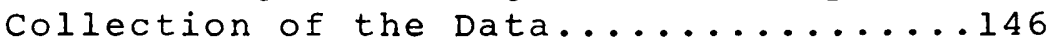

Sampling of Attributes............147

V. Findings and Conclusions.................... 49

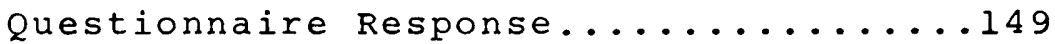

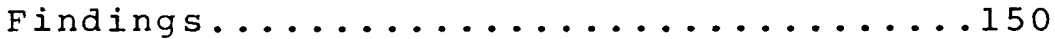

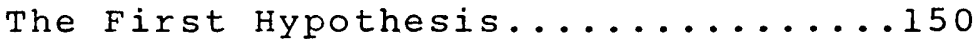

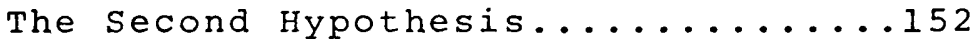

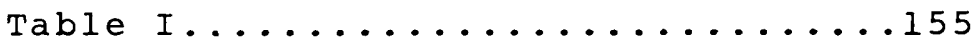

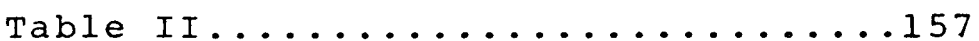

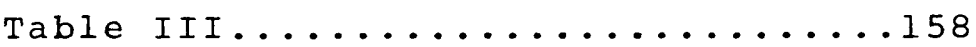

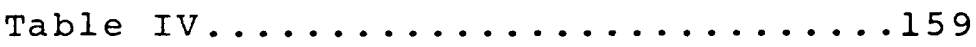

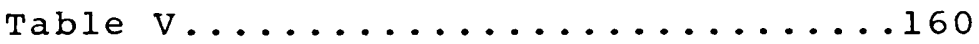

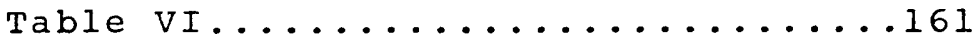

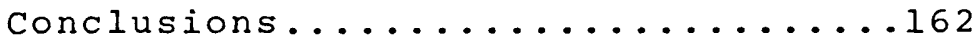

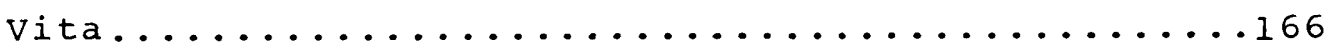

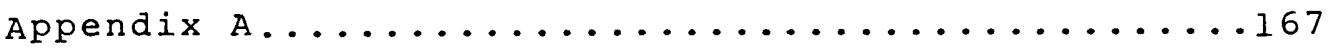

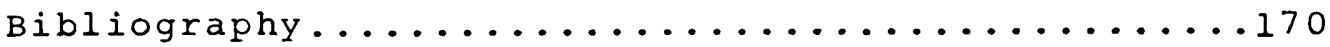


We would like to express our sincere appreciation to Dean Gerald Lattin for his guidance and advise during our academic years at F.I.U.

We would also like to thank Dr. Greenaway for his pertinent advice and assistance in making this thesis possible.

We would like to express our gratitude to professor Ilvento for his guidance in the independent research section of our thesis.

We would also like to thank our parents for making our graduate education possible. We appreciate the support of our parents and friends and for being there when we needed them. 
Abstract

The purpose of the study is to examine the impact of the timesharing concept on the resort industry in order to determine the industry's familiarity with timesharing and the industry's conception of the present and future effects of timesharing.

The study utilizes two methods of research, primary data and secondary data, to examine the concept of timesharing. The secondary data is used to examine the various components of timesharing. This section includes information on the different forms of timesharing, the legal aspects, the marketing, management, finance and future of timesharing in order to educate the public about the concept.

The primary data takes the form of a survey that questions hotel/motel operators in the Fort Lauderdale Beach area to determine their attitudes towards the impact of timesharing on the resort industy. 


\section{THE PROBLEM AND ITS SETTING}

Statement of the Problem

The purpose of the study is to examine the impact of the timesharing concept on the resort industry in order to determine the industry's familiarity with timesharing, and the industry's conception of the present and future effects of timesharing.

Statement of the subproblems

The first subproblem is to determine whether timesharing is a natural extension of the resort industry or of the real estate industry and in which sector it exerts the most influence.

The second subproblem is to determine whether timesharing is specifically suited only for these times, or will it become a firmly established concept in the future. The Hypothesis

The first hypothesis is that timesharing is a natural extension of the resort industry.

The second hypothesis is that timesharing is suited for these times, and is capable of becoming a firmly established concept in the future. The Delimitations

This will be limited to hotels/motels in the Fort Lauderdale beach area. (Directly on the beach; and directly across from the beach) 
Definition of Terms

Timesharing - is the buying or leasing of a vacation

home in increments of a week or more by a number of buyers, each of whom purchase only the time which they will use each year.

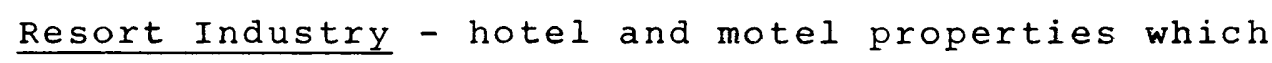
provide recreation and entertainment to visitors, in and offer transient rooms to guests.

\section{Assumptions}

The first assumption is that the timesharing concept is flexible and can be adapted to changing social and economic conditions.

The second assumption is that the timesharing concept will continue to grow.

The Importance of the study

Timesharing is a relatively new concept. Its impact on vacation lifestyles and hotel/motel real estate is vital. The timesharing concept has been the subject of increasingly more attention over the last five years, but the considerable difficulties with regard to timesharing have received inadequate attention. ${ }^{1}$

Timesharing allows the purchaser the use of a second home without the financial burdens of second home ownership. The purchaser invests only in the time period during which he believes he would use the vacation home, with each time period representing a share of the year. In comparison to 
renting hotel accommodations year after year, timesharing promises vacationers long-term savings because of a project's reduced overhead and operating expenses. Also because a sold-out timeshare project theoretically enjoys 100 - percent occupancy, a projects expenses were spread over a large number of room-nights than is typically the case in a conventional hotel. 2

Timesharing is quickly becoming a vibrant, innovative field in which entrepreneurs are seeking or creating firstclass resort condominiums designed to offer outstanding facilities to an ever-growing market. More than $30 \%$ of all Americans can afford one or more timesharing periods, as compared to less than $5 \%$ who may be able to pay for a second home or condominium. 3

Vacations are essential to Americans, as are fun places to enjoy them. Rising costs and inflation have made it difficult for the average man to enjoy his free time as resort rates have increased over $80 \%$ in the past ten years. The hotel/motel field may be in a good position to capitalize on this phenomenon, because quite a few of its existing resort properties may possess the facilities and amenities to satisfy the potential timeshare purchaser at - prices lower than duplication costs of new properties. All those involved in the resort industry must keep an eye on timesharing and its likely impact on the hotel industry. 4 
${ }^{1}$ steve Brenex, "Time-Sharing Makes Its Mark." Lodging Hospitality, (June 1978), p. 38 .

${ }^{2}$ Christopher W. Hart, "Timesharing: Part of the Hotel Equation." The Coxwell H.R.A. Quarterly (November 1980), p. 50 .

${ }^{3}$ Brener, op. cit., p. 38 .

${ }^{4}$ Hart, op. cit., p. 38 . 
Timeshare ownership of resort accommodations is growing rapidly in resort communities throughout North America, Europe, and elsewhere. Nearly any resort with an established tourist trade is experiencing timeshare development through the construction of new units or the conversion of existing condominium or hotel units. Ir addition, timeshare development is becoming apparent in communities with little previous experience with tourism. Although the majority of timeshare development is in the form of condominium units, other forms of accommodations also are being offered on an interval basis, including detached units and facilities such as yachts, oceanliners, and camping and recreational vehicle facilities. It is evident trat timesharing, as a form of ownership, can be applied to a wide range of recreation and other facilities as the market becomes receptive. ${ }^{1}$

Timesharing is a relatively new concept which is not always consistent with commonly held conceptions about ownership of property. The purpose of tinis study is to provide general information on timesharing in order to educate the public and eliminate misconceptions. By providing current and valid data specific to resort timesharing, decisions made in the future by developers and buyers will not have to be made in an informational vacuum. 2 
In order to provide the necessary background information on timesharing this study contains a review of the relevant related literature. Included in this section are the results of a study conducted for the American Land Development Association's Resort Timesharing Council. by Richard Ragatz Associates Inc.

Questionnaires were mailed to 20,730 timeshare buyers from thirteen of the sponsoring companits who either have developed and/or marketed timeshare projects. Thirty-three projects are representied by these thirteren sompanies. Another 6,000 questionnarires were mailed tre members of the two exchange comparits, Hncludinss 3.500 menbers of Resort Condominiums International and 2.500 mentors of Interval International. Some 9,685 usable questionaires were returned for a very tijgb response rat: af 36.3 percent. Approximately five parsent or a li existimg timeshare owners in the country parricipated in the surrew. Based upon statistical sampling theory, the häh rate of return coupled with the sizeable representation of the overall population, are more than enough to conclude that the survey results are reliable. 3

Comparative references are frequently made in the study - to a 1978 survey conducted by the author and sponsored by Resort Condominiums International. Theste comparisons should give insights into how the timeshare market has changed in the past two years. The 1978 survey was conducted of 1,564 
RCI members from sixty-one different projects, with the methodology and many of the questions being exactly the same as in the 1980 study. 4 
Percent of Respondents By Reason for Purchase

\begin{tabular}{ccccc} 
Variables & $\begin{array}{c}\text { Investment } \\
\text { Resale }\end{array}$ & $\begin{array}{c}\text { Exchange } \\
\text { Opportunity Recreation }\end{array}$ & $\begin{array}{c}\text { Liked Save Certainty } \\
\text { Unit Money of Accom. Property }\end{array}$ \\
\hline
\end{tabular}

A. Age of Household Head

$\begin{array}{ll}\text { Under } 25 & 48.5 \\ 25 \text { to } 34 & 46.0 \\ 35 \text { to } 44 & 38.0 \\ 45 \text { to } 54 & 36.4 \\ 55 \text { to } 64 & 34.1 \\ 65 \text { or older } & 39.4\end{array}$

$\begin{array}{lllllll}48.5 & 82.6 & 19.0 & 19.0 & 71.1 & 19.7 & 20.3 \\ 46.0 & 79.2 & 22.4 & 23.0 & 71.3 & 18.7 & 21.0 \\ 38.0 & 72.0 & 30.3 & 26.7 & 64.1 & 23.7 & 22.6 \\ 36.4 & 71.1 & 30.2 & 33.5 & 57.8 & 24.0 & 24.1 \\ 34.1 & 65.7 & 31.4 & 36.5 & 48.7 & 29.5 & 24.8 \\ 39.4 & 60.4 & 30.2 & 40.5 & 39.8 & 29.1 & 23.6\end{array}$

B. Household Income

$$
\begin{aligned}
& \text { Under } \$ 15,000 \\
& \$ 15,000 \text { to } \$ 19,000 \\
& \$ 20,000 \text { to } \$ 24,999 \\
& \$ 25,000 \text { to } \$ 29,999 \\
& \$ 30,000 \text { to } \$ 39,999 \\
& \$ 40,000 \text { to } \$ 49,999 \\
& \$ 50,000 \text { to } \$ 99,999 \\
& \$ 100,000 \text { or more }
\end{aligned}
$$

c. Type of Consttuction

$\begin{array}{ll}\text { New for timeshare } & 22.0 \\ \text { Conversion from condo } & 43.9 \\ \text { Conversion from hotel-major } & 43.3 \\ \text { Conversion from hotel-minor } & 16.5\end{array}$

$$
\begin{aligned}
& 47.4 \\
& 43.3 \\
& 39.2 \\
& 38.3 \\
& 37.7 \\
& 35.8 \\
& 37.3 \\
& 39.5
\end{aligned}
$$

$$
\begin{aligned}
& 65.5 \\
& 71.2 \\
& 73.6 \\
& 77.9 \\
& 74.3 \\
& 72.3 \\
& 65.2 \\
& 56.0
\end{aligned}
$$

$$
\begin{aligned}
& 21.7 \\
& 23.3 \\
& 25.7 \\
& 25.1 \\
& 27.9 \\
& 32.7 \\
& 35.6 \\
& 43.6
\end{aligned}
$$

75.2

76.9

74.1

86.3

\begin{abstract}
33.4
27.8

21.0

25.1
\end{abstract}

$\begin{array}{lll}27.0 & 64.0 & 20.8 \\ 29.1 & 63.7 & 19.8 \\ 29.2 & 66.7 & 22.0 \\ 29.2 & 64.3 & 23.8 \\ 28.7 & 61.6 & 23.5 \\ 33.0 & 56.5 & 24.4 \\ 33.7 & 48.7 & 28.1 \\ 37.4 & 35.8 & 38.7\end{array}$

$\begin{array}{llll}25.7 & 59.4 & 20.8 & 20.3 \\ 30.9 & 58.0 & 25.2 & 27.9 \\ 18.4 & 63.5 & 32.9 & 29.3 \\ 21.5 & 87.7 & 33.7 & 16.1\end{array}$


1. U.S. Reports

Resorts in more than half of the states have timeshare facilities. The leaders are Hawai, Florida, California, Colorado, South Carolina and Texas.

1973 and earlier 8

$1974 \quad 23$

$1975 \quad 45$

$1976 \quad 70$

$1977 \quad 140$

$1978 \quad 240$

$1979 \quad 350$

$1980 \quad 425$

$1981 \quad 550-600$ (estimated)

2. Number of Foreign Resorts (as of 1980)

Europe, Africa, Near East 100

Mexico 50

Caribbean 20

Australia, New

Ziealand, Fiji 12

Latin \& South America 6 (except Mexico)

Canada

12

Far East

Total

$2 \frac{6}{06}$

3. Industry sales

1975 (first year of $\$ 50$ milition appreciable activity in U.S.)

1976

1977

$\$ 75$ million

1978

\$150 million

1979

$\$ 300$ million

1980

$\$ 650$ million

1981

$\$ 800$ million

1982 (Projected)

$\$ 1.3$ billion

$\$ 1.5$ billion 
4. Number of people who own a timeshare

$\begin{array}{lrl}1975 & 10,000 \\ 1976 & 25,000 \\ 1977 & 56,000 & 120,000 \\ 1978 & 200,000 & \\ 1979 & 270,000 \quad \text { (these } 270,000 \\ 1980 & \text { families perhaps } \\ & & \text { have purchased up } \\ & 50 \text { 500,000 weeks) } \\ 1981 & 350,000 \text { (estimated) }\end{array}$

5. Number of companies

Approximately 300 companies in 1979; approximately

350 in 1980. At least 50 companies are exclusively

involved in timesharing. In 1979 about 10 companies

had sales in excess of $\$ 10$ million annually, in

1980 and 1981 approximately 20 were in this

category. 5 
${ }^{1}$ Richard Ragatz, The Ragatz Study, (Washington, D.C., The Resort Timesharing Council of the American Land Development Association, 1979), p. 5 .

2

Ibid. p. 2 .

${ }^{3}$ Ibid. p. 4

4 Ibid. p. 13

5 American Land Development Association, Resort

Timesharing Fact Sheet, (Washington, D.C., 1982), p. 2-3. 


\section{History}

The term "timesharing" is American. It is borrowed from the computer industry where the concept of sharing the expense of using costly computers has been utilized for many years. However, the concept of timesharing as applied to accommodations, has its origins in Europe.

The first timeshare projects were established in Europe in the mid-1960's. This interval resort sharing originated in Europe where vacation lodging is scarce and expensive ${ }^{1}$ and where inflation was felt earlier than in America. ${ }^{2}$ It was developed as a means of increasing year-round occupancy ${ }^{3}$ providing some reservation security ${ }^{4}$ and of making vacation homes available to Europeans at relatively low prices. 5 These European resorts and the few U.S. resorts that developed in the early stages employed the "right-to-use" method of timesharing. The concept of interval ownership originated in America.

Although timesharing began in the U.S. in the late 1960's, the vacation concept did not become popular until the mid-1970's. Condominiums were in demand and were the trend in the American real estate industry until the recession and real estate crash which occured in the mid-1970's. At this time developers found themselves holding large quantities of condominium units which they could not sell. The desire of developers and mortgagers to recapture their investments and the high inflation rates which pushed housing costs out 
of the reach of many families, led many builders to turn to the European idea of dividing real estate among several buyers. Later, the concept spread to hotels and motels as well as to campgrounds and yachts. Americans have borrowed the timesharing idea from Europe and the term From the computer industry to come up with a relatively new way to vacation in the U.S.

Some observers suggest that timesharing was forced by the overbuilding of condominiums in a depressed market. However, few developers converted to timesharing at that time, but instead chose to hold on to their condominium developments and wait for better times. 6 Although some people felt that the timesharing concept was a product of hard times which would disappear with recovery: believers in timesharing felt it to be a natural evolution of the second-home industry. 7 Timesharing has become firmly established concept; the real estate wave of the 1980's, as it offers vacation home ownership to everyone. 8 
l"Vacation Time sharing ... Catching on," sunset (oct. 1980), p. 62 .

2 Elizabeth Guest, "How to Vacation Like the Rich People Do," Next (June 1981), p. 2 .

${ }^{3}$ Keith w. Trowbridge, "A Slice of Time," Real Estate Today, (March 1980), p. 37 .

${ }^{4}$ Ibid. p. 736 .

5

${ }^{5}$ Guest, op. cit., p. 2 .

${ }^{6}$ Keith w. Trowbridge, Resort Timesharing (New York, Simon and schuster, 1981), p. 25 .

7 Thomas J. Davis, Jr., "Time-sharing Exchange Networks," Real Estate Review, (Fall 1978), p. 43 .

8 Bruce Chadwick, "Buy Time," House Beautiful (Oct. 1979), p. 91. 
While there are endless variations in resort timesharing, basically all programs can be classified as either ownership or right-to-use. Typically, both ownership and right-to-use programs sell increments of one week in a specific unit. Two weeks are usually set aside annually for thorough cleaning, maintenance, repairs and refurnishing. The most common system for interval vacation selection is by fixed week. Under this system the purchaser selects one or more specific weeks on the calendar and gains the exclusive right to occupy a specific unit for a fixed time period annually. The other system is called a floating week. Under this system a person purchases within a season or price range and gains an occupancy right within those ranges annually on a first-reservation, first-confirmation basis. ${ }^{l}$ It is also possible in some programs to have a fixed week and a floating unit. Generally the fixed week is used in ownership programs while floating systems are more prevalent in right-to-use programs in which no deed is involved. Timesharing can be structured to accomplish almost anything. Resorts can use it to generate off-season traffic through differences in pricing or by combining on-and-off season periods into one time-share etc. ${ }^{2}$ various timesharing programs offer different amounts of flexibility and different advantages to the buyer. 
Types of Timesharing

Ownership plans

Ownership plans provide the owners with equity interest in the resorts. Shares of time are sold as a part ownership of real estate. Customers buy into the resort as they would buy any property, but their deeds cover only a specified week or weeks each year. The deed for a particular fraction of the property entitles the buyer to the same privileges and liabilities that owners of any real estate receive. Timesharing ownership sales are real estate transactions and therefore require the services of licensed real estate salespersons.

The most widely used and most popular type of ownership is interval ownership. It involves a two-part arrangement whose transition does not require separate documentation. The first part is an estate for years under which a person owns the unit for the purchased number of weeks, every year for a specified number of years. The number of years usually corresponds to the estimated useful Iife of the building. At the end of this specified number of years the second part automatically comes into play. At this time the owners of all the time periods become tenants - in common in the ownership of the unit. This undivided interest in the unit is usually based on predetermined percentages, in proportion to the number of weeks previously owned by each individual. Each estate is separately owned 
and therefore is immune to tax liens on the other owner's interests.

Time span ownership is a less frequently used type of interval ownership. It is based on the idea of tenancy in common, from the beginning. The purchaser acquires an undivided interest in the whole unit based on the length of the time period selected. The particular time period that each owner will use is established by a separate agreement; an occupancy agreement.

Both types of timeshare ownership protect the purchaser by giving him title to the property and title insurance. Each owner has the right to sell, will, rent, lend or transfer ownership of his time periods and his interests. There are many advantages for the purchaser of the ownership form of timesharing. Although a resale market has not yet been established, there is a great potential for equity build-up and possible appreciation. Each owner may mortgage his share, write off the interest on his income taxes and take deductions on real estate and personal property taxes. 3 ownership interest may give the purchaser a stronger voice in the management of the project. Also it may be easier for the purchaser to find financing. Advantages to the developer include somewhat easier access to financing and the eventual assumption of many of the management duties by the property owners association. 4 
There are also disadvantages or potential disadvantages to the ownership type of timesharing. While ownership means that the purchaser has more say in how the buildings and facilities are managed and maintained, the purchaser has more responsibility to participate in the property owners' association. Many ownership projects operate on a fixed week/fixed unit basis and lack flexibility. There are two potential disadvantages which have no effect during the initial estate for years but which may have an effect during tenancy in common. These concern partition and federal tax liens. Tenancy in common allows a co-owner the right to sue for partition. Any owner could sue to have the building sold and the proceeds distributed pro rata mong the co-owners. This problem can be solved by including a waiver of partition among the covenants that each purchaser accepts when he accepts his deed. Also, the government can force a partition in order to satisfy a tax lien against an individual owner. However, this risk seems to have been satisfied by the Internal Revenue ruling 79-55 (1979) in which the IRS ruled that a timeshare interest is "separate and distinct" and is "capable of being sold without selling the unit itself." 5

\section{$\underline{\text { Right-To-Use }}$}

Right-to-use timesharing offers the participant a contractual agreement, but there is no ownership involved. The agreement lasts for a determined period of years. Some 
plans offer short term programs of 10 to 15 years, while others offer extended programs that last for as long as forty years. At the end of the right-to-use period, the occupancy reverts to the original resort owner or club who then determine the future of the share. Often the owner will review the option at the original price or one which is mutually beneficial. 6 It is appropriate to view rightto use as a form of long term advanced booking of a specific type of accommodation. The occupancy privilege in a right-to-use plan is established by a contract between the purchaser and the hotel or club that owns the accommodations. Since there is no real transference of property, it is possible to keep the contract fairly basic. Generally, it will specify the type of unit the individual can use, the quality standards that will be maintained, how he can use his annual time, the duration of the plan, and other appropriate conditions. 7

Right-to-use is most often offered by hotels or motels because they find it to be more practical than interval ownership. They can divide their property, converting a portion of their rooms to timesharing, while still maintaining a portion of their rooms for conventional use.

There are a number of reasons why a resort would prefer right-to-use ownership, rather than another form of timesharing. The legal and financial burdens for the owner in partioning for individual ownership may be too great. 
The owner may also find the right-to-use alternative to be beneficial since he can maintain the balance of the property as rental apartments. A developer may find that local zoning ordinances prohibit the sale of timesharing but do permit leases on properties which may extend to ninety-nine years. Therefore, although right-to-use may be the only choice, it could still remain as attractive as ownership. The developer may wish to retain ownership of the property, and make alternate plans for its use at the termination of its internal use. Generally, from the point of view of the developer, the decision on whether to use right-to-use or interval ownership is determined by which type is most feasible and practical given the conditions at hand. 8

There are three principal forms of right-to-use that are in use today. The three forms are vacation licenses, vacation leases, and club membership.

Vacation license is the oldest form of timesharing in the United States. The developer and purchaser draft an agreement which stands as the license. The purchaser is given the use of a particular piece of real property for a specified time period each year. The life of the license is limited by the agreement and can run from five to forty - years. The license was developed as a means of avoiding real estate salesmen. Several states have already ruled that the license is actually an interest in real property and therefore must comply with state real estate regulatory agencies. In order to avoid unexpected legal problems, 
the license should be treated in a similar manner as a lease. In this way, the real estate nature of the transaction would be acknowledged and it would comply with the requirements of real estate regulatory agencies.

Under the vacation lease, the purchaser acquires a lease for a particular piece of real property for a given period each year. The lease extends for a specified time period. The agreement is the same as one between a landlord and a tenant. All of the rights and obligations of both parties are stated in the lease.

The basic-difference between the vacation lease and the vacation license is the admission of the developer in the case of the lease that he is selling an interest in real property and is therefore subject to the jurisdiction of the various real estate regulatory bodies.

Club membership is the only form of right-to-use timesharing that can legitimately claim no interest in real property, and is therefore not subject to the jurisdiction of real estate regulatory bodies. club membership usually takes the form of a non profit corporation set up to provide time for its members. The time may be provided in a specific resort or in a number of resorts. - The members generally receive the right of a specific time period each year, for a given term of years. The rights and obligations of the developer and the members are determined by the articles and bylaws of the nonprofit 
organization or club and by the membership agreement between the developers, the club and the member. 9

The greatest potential risk in the right-to-use program stems from the fact that members do not have the security of an ownership interest in the property. There is only a contract which obligates the owner of the facility to provide the purchaser with accommodations for a long time into the future. This creates two possible risks. The purchaser is at the mercy of the management to deliver service year after year. Although he has no direct voice in how the place is run, he does have a contract, and can therefore expect a particular level of service. If the contract is breached, all members have the recourse of legal action.

The other major $r i s k$ is that a property may have one or more mortgages; and there is a possibility that the purchaser's occupancy might be jeopardized if it is not legally recognized, through what is known as a nondisturbance clause in the mortgage, the lender is not legally obligated to fulfill his contract, and the lease could be lost. 10

In addition to the risks, there are other negative - aspects of right-to-use, or non-ownership. As a non-owner the individual is not building equity in his investment. There are no restrictions on the sale of the resort during the purchaser's term of use, and he has no input as to 
the decision on the buyer. There are restrictions on the resale of right-to-use unit weeks. This generally does not affect bequeathing one's membership, giving it away as a gift, or allowing others to use it. The reason for the restriction on resale is that developers seek to avoid violating the restrictions of the securities Exchange Commission which prohibits the selling of investments for a profit without having registered with them. Registering with the SEC is a very expensive procedure, and one which most developers do not feel is a necessary expense. There are a number of advantages to investing in right-to-use ownership. These units are generally less expensive. Ultimately the property reverts back to the owner and he therefore has a personal interest in keeping the property in excelient condition. This makes renewal and resale possibilities greater for him.

Another advantage of right-to-use is that the management operations of these properties generally stem from hotels and motels. Therefore the people are usually very experienced and competent at what they are doing. The paperwork is simpler under right-to-use and closing fees are less. AIl that is necessary is that the buyer - pay his money, and get a certificate of occupancy for the particular time period and for the number of years offered..$^{1}$ 
${ }^{1}$ Keith W. Trowbridge, Resort Timesharing, (New York, Simon and schuster, 1981), p. 39 .

2 Natalie Gerardi, "Timesharing." House and Home, (November 1974), p. 72 .

${ }^{3}$ Jill Bettner, "For Economical Luxury, Try Resort Time-Sharing," Business Week, (June 4, 1979), p. 121 .

4 Dennis G. Dunn, "Lending to the Resort Timesharing Industry," The Journal of Commercial Bank Lending, (August 1981), p. 28 .

${ }^{5}$ Ibid., p. 29.

${ }^{6}$ Trowbridge, op. cit., p. 34 .

${ }^{7}$ Carl Burlingame, The Buyers Guide to Resort Timesharing (California, 1981), p. 26 .

8 Trowbridge, op. cit., p. 34.

9 Thomas J. Davis, "Time-sharing Ownership: Possibilities and Pitfalls," Real Estate Review, (Winter 1976), pp. 50-52.

I0 Burlingame, op. cit., p. 30.

${ }^{11}$ Trowbridge, op. cit., p. 36 . 
It appears the typical consumer of timeshare is a married couple with one or two children. The household head is about 45 years of age and has at least a Bachelor's degree. They have an average annual income of between $\$ 30,000$ and $\$ 35,000$, and they live within 150 miles of their timeshare. They have bought a timeshare because it offers flexible vacation plans while at the same time holding down future vacation costs.

While it is relatively easy to characterize the "typical" consumer of timeshare, the preceding information also indicates that a tremendous variety exists in regard to each of the variables. Many consumers are young married coupleswithout children (or even single individuals), who want to buy recreational real property but have not yet had the time to accumulate sufficient capital for the wholly owned vacation home or resort condominium. older, retired couples also are consumers, perhaps because they want to avoid maintenance responsibilities associated with other types of recreational real property. Some people are buying timeshares within 25 miles of their primary home while others are purchasing a unit 1,000 miles or more away. In other - words, a norm can be described, but the range on either side of the norm is very extensive for almost every descriptive variable.

It does appear, however, that when aggregating the 
variables of age, education, income, and family type, the timeshare market is composed of a very stable population. Due to their high income and educational attainment, their middle-age and marital status, it would seem they are relatively protected from extreme problems with any impending recession in the country. This is especially evident in a market for relatively low cost recreational real

property such as resort timesharing where most units can be purchased for less than $\$ 5,000$ a week.

*Source: Richard L. Ragatz, for the Resort Timesharing Council of the American Land Development Association, 1979 . 
A. Household Income

Under $\$ 15,000$
$\$ 15,000$ to $\$ 19,999$
$\$ 20,000$ to $\$ 24,999$
$\$ 25,000$ to $\$ 29,999$
$\$ 30,000$ to $\$ 39,999$
$\$ 40,000$ to $\$ 49,999$
$\$ 50,000$ to $\$ 99,999$
$\$ 100,000$ or more
Total
Sample size

$\begin{array}{rr}5.7 & 7.7 \\ 9.0 & 14.5 \\ 13.9 & 20.3 \\ 15.0 & 19.1 \\ 24.3 & 20.1 \\ 14.9 & 9.0 \\ 14.5 & 8.4 \\ 2.6 & 0.9 \\ 100.0 & 100.0 \\ 9,365 & 1,505\end{array}$

B. Age of Household Head

Under 25

25 to 34

35 to 44

45 to 54

55 to 64

65 or older

Total

Sample size

Median years

C. Type of Household

single individual

Male

Female

Married couple

Total

Sample size

$\begin{array}{rr}3.2 & 1.4 \\ 19.2 & 22.8 \\ 22.3 & 23.9 \\ 30.4 & 31.6 \\ 20.1 & 17.1 \\ 4.8 & 3.2 \\ 100.0 & 100.0 \\ 9,516 & \mathrm{n} . \mathrm{a} .\end{array}$

10.6

5.3

5.3

7.4

$\frac{89.4}{100.0}$

$1 \frac{92.6}{100.0}$

8,727

1,551

D. Number of Children at Home

One
Two
Three
Four
Five or more
None
Total
Sample size
Average

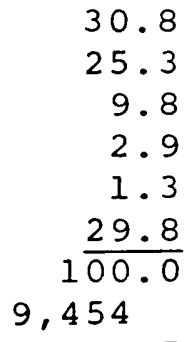

1.5
16.7

23.8

12.3

5.8

2.0

$1 \frac{39.4}{100.0}$

1,556 
Table III (Continued)

Characteristics

Percent of Respondents

1980 RTC Survey 1978 RCI Survey

E. Education of Household Head

$\begin{array}{lrr}\text { Less than high school degree } & 3.1 & 3.2 \\ \text { High school degree } & 21.0 & 22.5 \\ \text { Some college } & 20.9 & 24.0 \\ \text { Bachelor's degree } & 23.5 & 22.3 \\ \text { Graduate work } & 31.4 & 28.0 \\ \quad \text { Total } & 100.0 & 1,530 \\ \quad \text { Sample size } & 9,384 & \mathrm{n} . \mathrm{a} .\end{array}$

F. Distance Between Home

and Timeshare Unit

Less than 25 miles

25 to 49

4.5

6.1

2.0

50 to 99

21.9

6.5

100 to 149

16.9

29.3

150 to 249

11.0

22.4

250 to 499

5.9

15.7

500 to 000

7.2

5.3

1,000 to 1,999

18.7

5.2

2,000 to 2,999

4.1

7.8

3,000 or more

$\frac{3.6}{100.0}$

5.8

Total

, 325

Sample size

Average distance

597.9 miles

$\frac{\mathrm{n} \cdot \mathrm{a}}{100 \cdot 0}$

1,515

G. Most Important Reasons

for Purchasing Timeshare

Exchange opportunity

Save money on future

vacation costs

Liked recreational facilities

Investment or resale potential

certainty of having

accommodations

Liked timeshare unit

opportunity to own

71.4 *

75.3 *

59.4

63.0

resort property

other

Sample size

28.6

38.6

38.8

38.0

24.1

31.0

30.4

30.0

23.1

27.1

(*Figures do not add up to 100.0 percent because respondents could check more than one answer.)

* Source: Richard L. Ragatz, for the Resort Timesharing Council of the American Land Development Association, 1979. 


\section{Marketing}

The marketing of timesharing, like the marketing of anything, entails knowing who the market is, and how to go about reaching them. The first step for a resort that plans on implementing timesharing is to do a feasibility study. This study should be a guide in such areas as who the potential customers are and, can these customers afford the price of the timesharing facility that you plan on developing. Also, to be considered is the operator's ability to obtain the capital, and to maintain the program for the term of the vacation plan.

When management considers timesharing it should consider location as its number one priority. It should consider the access of the resort; can it be reached by plane, bus or train? It should consider the motivation of its potential market; are they interested in the resort per se, or in the town as a whole? Seasonality and average length of stay should also be considered. Management must be prepared to sell the off-season weeks as well as the seasonal ones. ${ }^{1}$

The design of the project and the makeup of the timeshare facility should be developed as a result of the feasibility study and should meet the needs of the market and the specific requirements of the project's location. These needs must be considered when determining the physical design for a particular location. For example, in this 
way small units are not built in a location which is usually visited by families on one month vacations. The marketing function is the critical variable that determines the projects profitability.

A high degree of sophistication in sales and marketing is required in order to sell out a property, profitably and ethically and in such a way that consumers' past purchase satisfaction remains high. Achieving these aims are not easy for any marketing sales force. 2

There is a marketing strategy from which quality time sharing resorts develop variations to suit their needs. This strategy begins with the design of the project, because in timesharing the seller will be selling not only the housing unit, but also what goes inside. This gives the salesperson the opportunity to sell a top quality furniture package as well. It is necessary for timeshare developers to hire the services of a professional decorator, as a prerequisite to the marketing of their property. There is a risk that sales will be lost if people do not like the package that is produced. Product design affects the cost of maintenance as well as the price the seller will charge for the unit. 3

One of the most important factors is that the units must be priced competitively. The lower the prices per share, the larger the market. The ideal length, is the longest period, that will yield a low enough price, and appeal to 
the widest possible market. Generally, the best way is on a fifty-two week basis. This system allows maximum flexibility. It also precludes the need to change legal documents if longer time segments do not sell well. With one week time periods, it is easier for prospective purchasers to mix time periods to suit their particular needs. It is necessary to determine the vacation pattern of the market. This can be done by gathering data on hotel and motel registration, automobile rentals, and other seasonal business in the area. By using these sources it is possible to determine the preferred length of stay of the market. 4

To market a property effectively it is necessary to know the competition. For most timeshare resorts that competition is the local hotel or motel in the area, not the people who are interested in buying a second home. It is generally worthwhile for the time share resort to prepare a comparison of how much it would cost to pay off the price of the timeshare and how much it would cost to vacation in a hotel over a period of years. The cost of vacationing in a hotel goes on forever, but a timeshare unit would be paid off in a number of years and future - vacations would be virtually free, except for maintenance costs. 5

There are a number of marketing techniques that are most often used to draw interest in timesharing. These 
techniques consist of, direct mail, telephone, booths in shopping malls and trade shows, outside personal contact and overnight visits or mini-vacations. The people who are marketing time sharing facilities prefer these methods over conventional media, such as newspaper, magazine, radio or television advertising, for a number of reasons. The time sharing idea is so new that a large amount of the public does not understand it. The concept needs in-depth explanation. This makes preparation of an effective newspaper article difficult because the ad must sell both the concept and the project itself. Marketing time sharing involves educating the public. It has been found that the most success comes from a one to one discussion, where questions can be answered and confusion can be alleviated. 6 Direct mail, if handled properly, is the best method of generating controlled prospects. Controlling the prospects entails determining who to mail to. There are two kinds of lists. Horizontal lists can be refined to include only people who earn certain incomes, or who live in single family homes, have a certain number of cars etc. Vertical lists are limited to particular groups such as golfers, boatowners, etc. Vertical lists provide three to five times the response received from horizontal lists. However, the problem with vertical lists are that they are much smaller then horizontal lists and they can only be relied upon for a small portion of the business needed. 
Direct mail generally includes offering prospects some type of a gift or a premium for visiting the project or for going to a sales party. It is through the premiums that the developer can control when the prospect will arrive, and therefore can arrange to spend enough time with each one. 7

The outside public contacts (OPCs) make use of an old land sales technique known in the trade as "body-snatching." OPCs, are hired to walk up to tourists on the street and offer them some sort of an inducement, such as a dinner for two, to visit the sales pavilion or timeshare project. OPCs are effective in generating large numbers of prospects. However, they are also acquiring a notorious reputation for high pressure tactics. Marketing costs are very high causing tremendous pressure on the salesman to move the merchandise. This often causes the salesman to try and get an immediate sale from a buyer, on his first visit to a property. This tactic, if continued with it's present zeal can result in being destructive rather than constructive for the marketing of time sharing. 8

A sales technique that is gaining popularity is the new one-stop, inclusive tour charters. These combine low - airline charter fares with ground arrangements. Often the total price is lower than the standard airline fare alone would be. Developers book their prospects on tours organized by tour operators. They are tailored to the 
specific needs of timesharing programs. The prospects are brought directly to the resort, and they pay most of the vacation expense. This sharply cuts the developers marketing costs, and helps to pre-qualify the prospect. The prospect knows before he signs up for the trip that he will be exposed to but not obligated to buy a timesharing offering.

This technique also helps to minimize the likelihood of buyer remorse, since the prospect has had the opportunity to stay at the resort, and to develop a feeling of confidence in his investment. 9

There are a number of factors that make the marketing of timesharing a particularly difficult operation. Among these factors are seasonal demands, the great expense, and the legal restrictions faced by sales people.

Two methods have been used to deal with heavy seasonal demand differences. A relatively unsuccessful approach has been to artifically force the purchase of off-season and prime time in a purchase package: for example, the developer might require that a week in November be bought in combination with a week in July.

Another way to deal with seasonal demand is through - differential pricing; pricing the peak season as high as the market will bear and the other seasons at artifically low prices in order to attract bargain hunters. This method enables the developer to make his investment 
profitable by selling only what is easiest to sell, the peak season, and he does not have to sell out completely in order to profit. Low season sales then become extras which are not essential to success and are therefore not worthy of any extensive sales effort. Low pricing may actually increase off season sales substantially as the consumer perceives a bargain. Differential pricing can reduce the marketing cost considerably. 10

The selling of timesharing involves mass marketing since there can be anywhere from 5,000 to 20,000 shares that must be sold. As a result of the number of shares that must be marketed and the additional time-consuming sales effort necessary to educate the consumer about an unfamiliar concept, cost of sales can be anywhere from 25-45 percent of the sales price. This can be compared with the usual 10-12 percent for traditional condominium sales.

The cost of sales obviously has a significant impact on pricing. To cover their increased costs, developers having generally marked up timeshares by 25-30 percent over whole unit prices. These high prices raise questions about the product. There is already an awareness on the - part of the consumer that the total of timeshares adds up to more than the whole unit cost. Purchasers have been willing to accept this discrepancy, mainly because current timeshare prices are competitive with vacation 
costs in a rental unit. But when the cost of timeshares no longer adds up to a long term vacation savings, buyers will refuse to accept the high markups. 11

Sales people in the timesharing field have to take particular care in selling timesharing as an investment. Very few timeshare developers have registered their property as a security with the SEC. This is a very expensive procedure and one which most developers try to avoid. Without this registration with the SEC it is illegal for a sales person to make his pitch stressing investment opportunity. Instead the salesperson should emphasize that a timeshare should not be purchased for appreciation in value but rather for enjoyment. 12

Choosing a sales force is a very important factor in determining the success of the marketing effort. The timeshare salesperson is charged with the one-time sale of a high-priced product with which consumers are generalIy unfamiliar. Not only do consumers require a great deal of product information, they have personal preferences, questions, and problems that can be handled properly by only the most competent professional sales personnel. The cost of generating sufficient prospects to sell out a project, differences in salespersons' closing percentages and skill in generating referrals can spell tremendous differences in sales and marketing expense. Exceptional salespeople can outsell others by a factor of two or three times. 
It is the responsibility of the developer to assemble a professional ethical organization for selling, or he must contract the sales function to an outside group with a good track record. 13

Who is buying timeshares? A report based on a survey of interval purchasers entitled, The Resort Timesharing Industry - A Socio-Economic Impact Analysis of Resort Timesharing, provides the following data:

- The average age of timeshare purchasers is 45.5 years. -Married couples make up $89.4 \%$ of the purihasers. -The average household size is 3.5 persons.

- Over $75 \%$ had attended some college, and almost $55 \%$ are college graduates.

- Over $86 \%$ state they are "satisfied" or "very satisifed" with their purchases.

-Almost $75 \%$ said they would buy again.

- The average family income of purchasers is between $\$ 30,000$ and $\$ 35,000$.

-One-third of purchasers live within 100 miles of the resort; two-thirds live within 250 miles.

- The purchases were paid for in cash by $32.4 \%$ of buyers.

-The purchases were financed by $67.6 \%$ of buyers.

- The average downpayment was $15.7 \%$ of the total cost of the timeshare.

-Average payback term was six years. 
In conclusion, the marketing of timesharing is still

a relatively new field. There is alot left to learn. But since marketing is one of the key factors in determining the future success of timesharing, it will most likely develop and grow with timesharing, and become a successful field in its own right. 14 
${ }^{I}$ Charles I. Ilvento, C.P.A., "Vacation Time-sharing Plans," Financing the Hospitality Industry, (May 1976), p. 16 .

2 Christopher W. Hart, "Timesharing: Part of the Hotel Equation," The Cornell H.R.A. Quarterly, (Nov. 1980), p. 56 .

"Natalie Gerardi, "Update on Timesharing" House and Home, (March 1976), p. 35 .

${ }^{4}$ Ibid.

5 Alyce Boster, "Marketing the Time-Share Unit," Real Estate Review, (Spring 1975), p. 106 .

${ }^{6}$ Gerardi, op. cit., p.86.

${ }^{7}$ Ibid., p. 86 .

${ }^{8}$ Carol E. Curtis, "Endless Vacation or Endless Headache," Forbes, (sept. 14, 19811, p. 116 .

${ }^{9}$ Gerardi, op. cit., p. 87.

10 Boster, op. cit., p. 106 .

${ }^{11}$ Ibid., p. 107

12 Dennis G. Dunn, "Lending to the Resort Timesharing Industry," The Journal of Commercial Bank Lending,

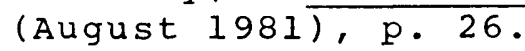

13 Hart, op. cit., p. 57.

14 Hart, op. cit., p. 58 . 
* Timeshare Characteristics

Over three-quarters of the respondents have purchased fee timeshares as opposed to right-to-use ones. While the true split between these two types of uses for all timeshare units in the country is unknown, it is definitely felt that the survey is exaggerated toward the fee type. In the 1978 survey, only 61.8 percent of the respondents had purchased a fee use which is probably much closer to the true split.

The results of the survey are discussed below. However, it is important for the reader to recognize the bias of the survey towards fee units and to therefore not generalize these summary findings to all timeshare units.

1. Average purchase price - Average purchase price for a week of timeshares was 18.1 percent higher for fee units than for right-to-use units $(\$ 4,050$ compared to $\$ 3,430)$.

2. Consumer characteristics - There seems to be a tendency for right-to-use timeshares to be more frequently purchased by buyers who are younger and have lower incomes and educational attainment. The validity of these generalizations is certainly suspect, however, due to bias of the sample toward fee projects.

Another characteristic of timeshare units relates to their type of construction. Over one-half ( 55.1 percent) 
of the respondents purchased timeshares in projects originally constructed for that purpose. About another one-quarter (26.0 percent) purchased timeshare units originally built for wholly owned resort condominiums. Some 14.7 percent of the respondents' units were converted from hotel/motel rooms. As with type of use, a bias exists in the survey since it is known that a greater proportion of existing timeshare units in this country are conversions, either from condominiums or hotels/motels. The bias is caused by the fact that most of the marketing/ development companies who sent questionnaires to their buyers have projects originally built for timeshare use.

1. Average purchase price - As might be expected, timeshares converted from hotels/motels with only minor renovations cost considerably less per week than do timeshares having other types of construction. For the most part, these units are usually considerably smaller and have fewer internal amenities. Their average cost per week was only $\$ 3,214$ as compared to $\$ 3,983$ for units originally constructed for timeshare, $\$ 4,000$ for units converted from wholly owned condominiums, and $\$ 4,021$ for units converted from hotels/motels with major renovations.

2. Consumer characteristics - Surprisingly, no well 
defined patterns seem to exist in regard to demographic variables and type of construction of timeshare units.

3. Consumer motivation - It is evident that many people buy smaller, less expensive converted hotels/motels units with minor renovations for the exchange opportunity and to save money on future vacation costs. For instance, 86.3 percent of the respondents buying this type of timeshare said they were motivated by the exchange opportunity whereas this alternative was not checked by more than 77 percent of the respondents in the other three type-of-construction categories. Apparently, many such buyers anticipate trading these smaller units for higher quality ones elsewhere around the country through the exchange privilege. On the other hand, very few of these buyers checked the motivational forces of "investment/resale potential" and "liked timeshare unit." Investment/resale potential was checked least frequently by owners of units converted from condominiums and ones converted from hotel/motel units with major renovations. "Liked timeshare unit" was checked most frequently by those 
owning units either unconverted from

condominiums or originally constructed

for timeshare.

The state-by-state location of respondents' timeshares shows that over one-half of the respondents owned their timeshares in Florida and Pennsylvania with other most frequently mentioned states being California, colorado, Hawaii, South Carolina, and Nevada. Such a distribution is of course caused by the fact that most sponsoring companies for this research project have their projects located in these seven states. The distribution does not represent the true spatial location of all timeshare projects in the country although it is known that probably the majority of them actually do exist in these states. By way of comparison, 76.0 percent of the respondents' timeshares were in these seven states, whereas 57.7 percent of the timeshare projects listed in a recently published directory are located in the same states.

1. Average purchase price - Timeshare units were most expensive in the major destination resort areas such as Hawaì, the West coast, Florida and the south Atlantic region (primarily Hilton Head Island). Average weekly purchase price was lowest in the New England and North Central regions. of course, prices vary tremendously from project-to-project within these regions. 
2. Age of household head - In regard to age, older respondents were most frequently represented in the west coast and especially florida. Younger buyers were most frequently represented in the Mountain region (probably due primarily to the higher degree of interest amongst this group in skiing) and the Mid-Atlantic and South Central regions (probably due to the lower cost of timeshare units and close proximity to the primary home which eliminates high cost of traveling). Otherwise, age distribution was not significantly different between the regions.

3. Household income - As might be expected, variations in income of respondents were most frequently represented in Hawi, West Coast, and Florida, while lower income respondents were most frequently represented in the Mountain, South central, Mid-Atlantic and New England regions.

It is evident from Table IV-A that resort timesharing is a very recent and rapidly growing commodity. over one- third (38.7 percent) of the respondents had purchased their unit within the past year and over one-half ( 53.4 percent) within the past two years. Conversely, only 9.1 percent had owned their unit for four years or more. 
Even though a recently offered commodity, over onehalf (52.2 percent) of the respondents already have purchased more than one week of timeshare (Table IV-B). Some 15.6 percent have purchased three weeks or more, compared to only 11.2 percent in the 1978 survey. The average number of weeks purchased was about 1.8 with the vast majority of respondents purchasing either one $(47.8$ percent) or two ( 36.6 percent) weeks.

Purchasers of multiple weeks tend to be older and higher incomed. For instance, whereas less than 25 percent of those respondents under 35 have purchased two weeks, this rate was about 43 percent for those over 55. This pattern is even more exaggerated for respondents owning three or more weeks. Also, whereas about 62 percent of the respondents with annual incomes less than $\$ 25,000$ owned one week, this proportion was only about 25 percent for those earning more than $\$ 50,000$. Thus, there is a very evident correlation between number of weeks owned and income as exemplified by the following summary table:

Approximate percent of

Annual Income

Under $\$ 20,000$

$\$ 20,000$ to $\$ 29,999$

$\$ 30,000$ to $\$ 39,999$

$\$ 40,000$ to $\$ 49,999$

$\$ 50,000$ to $\$ 99,999$

$\$ 100,000$ or more
Respondents Owning More than one week

$37 \%$

$42 \%$

$54 \%$

$60 \%$

$69 \%$

$81 \%$ 
It appears that as additional discretionary income becomes available, persons begin to collect more timeshares. It also becomes evident that the relatively inexpensive timeshare commodity is not just popular amongst the middle income and those with limited discretionary dollars. For instance, over one-quarter ( 27.7 percent) of the respondents with incomes over $\$ 100,000$ and 15.9 percent of those with incomes between $\$ 50,000$ and $\$ 99,999$ have already purchased four or more weeks of timeshare.

Related to number of weeks purchased is the issue of where these multiple week purchases are located. A vast majority ( 90.0 percent) of respondents own their timeshares at just one resort location, even though 52.2 percent own more than one week. While the remaining 10.0 percent proportion may appear low, it is interesting that some timeshare buyers are already beginning to collect not only multiple weeks but also multiple locations, even though being offered the exchange privilege with other locations. Timesharing has frequently had the image of attaining popularity only in peak vacation periods. Many observers of timesharing thus have criticized the concept due to perceived severe peaks and declines in seasonal use periods. - However, timeshare units have sold well during all seasons of the year. Based upon a sample of the almost 17,000 weeks purchased by the respondents, seasons range from a low of 23.9 percent in the fall to a high of 26.3 percent in the 
summer. Spring contained 24.8 percent and winter contained 25.0 percent.

The average cost of a week of timeshare as reported by all respondents was $\$ 3,935$. This figure is misleading, however, because it is historical in nature in that it includes timeshares purchased three or more years ago. It also aggregates all resort locations, seasons of the year, and sizes of units. While many timeshares still sell today for less than $\$ 1,500$ per week, this type usually is a studio or small one bedroom unit, in an off-season, and/or in a regional as opposed to destination resort area. Many larger timeshare units in peak seasons in quality locations currently sell for over $\$ 10,000$ per week. While the true national average for all timeshares currently being marketed is unknown, it probably more closely approximates $\$ 5,000$ to $\$ 6,000$ rather than the $\$ 3,935$ reported in the survey.

The summary data below show that over one-half (55.7 percent) of the timeshare weeks purchased by respondents cost less than $\$ 4,000$ per week. About one-third (33.4 percent) cost between $\$ 4,000$ and $\$ 6,000$ and 10.9 percent cost more than $\$ 6,000$.

\section{Cost Per Week}

Less than $\$ 2,000$ $\$ 2,000$ to $\$ 3,999$ $\$ 4,000$ to $\$ 5,999$ $\$ 6,000$ to $\$ 7,999$ $\$ 8,000$ or more Total
Percent of Weeks Purchased by Respondents

$$
\begin{array}{r}
9.4 \\
46.3 \\
33.4 \\
8.4 \\
2.5 \\
\hline 100.0
\end{array}
$$


It is found that average weekly purchase price varies considerably according to season in which the timeshare falls. For instance, averages were higher for the two peak seasons (summer with $\$ 4,128$ and winter with $\$ 4,038$ ) than for the two off-seasons (Spring with $\$ 3,769$ and Fall with $\$ 3,406)$.

The average price per week has increased since the inception of the market. For instance, respondents purchasing the timeshare within the past six months reported an average price of $\$ 4,456$ per week whereas this figure was only $\$ 3,297$ for respondents buying their unit four or more years ago. This represents about a 35 percent increase, which is probably less than overall inflation during the past four years, averaging about nine percent per year.

\section{Occupying Fee}

Table IV-E shows the average weekly occupying fee (including maintenance, per diem fee, etc.) increased from a reported $\$ 95$ in 1978 to $\$ 119$ in 1980 . This represents a 25.3 percent increase in two years.

Size of Timeshare Units

One of the most significant differences between the 1978 -and 1980 surveys was in size of the timeshare units. In 1978, over one-half ( 55.3 percent) of the respondents owned studios or one-bedroom units, and only 35.1 percent owned two-bedroom units. In the 1980 survey, these proportions were only 31.9 percent for studios and one-bedroom units and 60.2 percent 
for two-bedroom units (Table IV-D).

More detail in regard to size of timeshares is as summarized below:

1. Age of household head. Surprisingly insignificant variation is found between number of bedrooms and age of buyers.

2. Household income. As expected, higher income households are more frequent buyers of larger units (expecially those with three or more bedrooms) and lower income households are more frequent buyers of the studio units. Even with this variable, however, variations are not extensive.

3. Type of construction. Number of bedrooms does vary greatly, however, in regard to type of construction of timeshare project. For units which have been converted from motels with minor renovations, 66.6 percent were studios and 22.8 percent had one bedroom. Comparable figures for units constructed originally for timesharing were only 1.0 percent and 17.3 percent, and for units converted from wholly owned condominium units, they were only 2.1 percent and 12.4 percent. Conversely, 74.6 percent of units constructed originally for timeshare had two-bedrooms, while only 9.2 percent of those converted from hotels with minor renovations do so. 
4. Average purchase price. As expected, average weekly purchase price increases with size of

timeshare unit, being $\$ 3,399$ for a studio, $\$ 3,850$

for a one-bedroom unit, $\$ 4,001$ for a two-bedroom unit, and $\$ 4,342$ for a three-bedroom unit.

5. Average occupying fee. Also as might be expected, the average weekly occupying fee increases with size of unit, e.g., \$88 for a studio, \$1ll for a one-bedroom unit, and $\$ 124$ for a two-bedroom unit.

*Source: Richard L. Ragatz for the Resort Timesharing Council of the American Land Development Association, 1979 . 
A. Length of ownership

Less than 6 months
6 months up to 1 year
1 year
2 years
3 years
4 years or more
Total
Sample size

18.7
20.0
14.7
21.5
16.0
9.1
100.0
9,592

(62.0)

(combined)

(combined)

25.8

10.1

$\frac{2.1}{100.0}$

1,550

B. Weeks Purchased

1. Season purchased

summer

Fall

winter

spring

Total

Sample size (total

weeks purchased)

2. Total weeks purchased

1

2

3

4

5 or more

Total

Sample size

Average number of weeks

$$
\begin{array}{r}
47.8 \\
36.6 \\
6.9 \\
5.1 \\
3.6 \\
\hline 100.0
\end{array}
$$

9,491

1.8 n.a.

23.9

25.0

$\frac{24.8}{100.0}$

16,689

C. Average Purchase Price Per Week

$\begin{array}{lr}\text { Summer } & \$ 4,128 \\ \text { Fall } & 3,406 \\ \text { Winter } & 4,038 \\ \text { Spring } & 3,769 \\ \quad \text { Overall average } & \$ 3,935 \\ \quad \text { Sample size } & 7,132\end{array}$

n.a. 
TABLE IV (continued)

Characteristics

Percent of Respondents

$\overline{1980}$ RTC Survey 1978 RCI Survey

D. Size of Timeshare Unit
studio
1 bedroom
2 bedrooms
3 bedrooms
4 bedrooms or more
Total
Sample size
Average number of
bedrooms

E. Average Weekly Occupying Fee

F. How Many Different Locations of Timeshare Ownership

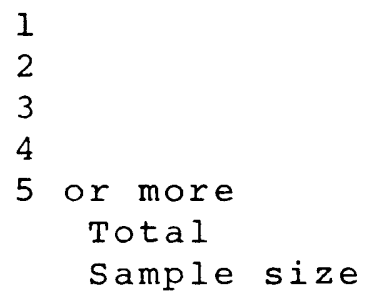

G. Type of Use Purchased

Fee

Right-to-use

Unknown

Total

Sample size

H. Type of Construction

New for timeshare

Conversion from condo

Conversion from hotel-major

Conversion from hotel-minor

Hotel unit as is

other

Total

Sample size

$$
\begin{array}{rr}
10.8 & 26.9 \\
21.0 & 28.4 \\
60.2 & 35.1 \\
7.4 & 8.9 \\
\hline
\end{array}
$$

$\frac{0.6}{100.0}$

9,353

1. 7

$\frac{0.7}{100.0}$

1,474

n.a.

$\$ 119$

$\$ 95$

$$
\begin{array}{r}
90.0 \\
7.7 \\
1.0 \\
0.2 \\
1.1 \\
100.0 \\
9,685
\end{array}
$$

$\mathrm{n} \cdot \mathrm{a}$.

77.5

18.0

$\frac{4.5}{100.0}$

9,685

$$
\begin{array}{r}
55.1 \\
26.0 \\
8.0 \\
8.7 \\
0.6 \\
1.6 \\
\hline 100.0
\end{array}
$$$$
8,105
$$

*Source: Richard L. Ragatz for the Resort Timesharing Council of the American Land Development Association, 1979. 
* TABLE A-2

Type of Use Purchased, By Selected Variables

Percent of Respondents By Type of Use Purchased

Variable Fee Right-To-Use Total

A. Age of Household Head

$\begin{array}{llll}\text { Under } 25 & 77.1 & 22.9 & 100.0 \\ 25 \text { to } 34 & 79.7 & 20.3 & 100.0 \\ 35 \text { to } 44 & 79.8 & 20.2 & 100.0 \\ 45 \text { to } 54 & 83.8 & 16.2 & 100.0 \\ 55 \text { to } 54 & 84.0 & 16.0 & 100.0 \\ 65 \text { or older } & 89.9 & 10.1 & 100.0\end{array}$

B E Education of Household Head

Less than high school degree

High school degree

77.1

22.9

100.0

80.6

78.7

19.4

100.0

some college

21.3

100.0

College graduate

85.5

14.5

100.0

Graduate work

83.9

16.1

100.0

C. Household Income

Under $\$ 15,000$

$\begin{array}{rrr}81.0 & 19.0 & 100.0 \\ 83.5 & 16.5 & 100.0 \\ 79.5 & 20.5 & 100.0 \\ 79.1 & 20.9 & 100.0 \\ 81.0 & 19.0 & 100.0 \\ 84.4 & 15.6 & 100.0 \\ 86.3 & 13.7 & 100.0 \\ 90.3 & 9.7 & 100.0\end{array}$

$\$ 15,000$ to $\$ 19,999$

$\$ 20,000$ to $\$ 24,999$

$\$ 25,999$ to $\$ 29,999$

$\$ 30,000$ to $\$ 39,999$

$\$ 40,000$ to $\$ 49,999$

90.3

9.7

100.0

$\$ 100,000$ or more

D. Average Purchase Price

$\$ 4,050 \quad \$ 3,430$

*Source: Richard L. Ragatz for the Resort Timesharing Council of the American Land Development Association, 1979. 
Timesharing is a two-part purchase. There is the payment for the interval itself and the ongoing annual maintenance or operating and management expenses. Timesharing is management. 1

A good percentage of industry analysts see management as the most critical element in the long-term success of the timesharing concept. ${ }^{2}$ The purchaser wants to make sure that his property will be well-taken care of and that his maintenance fee will be well spent. The bankers who finance the purchases want to insure that their end-loan securities will be valuable far beyond the terms of their notes. For the developer, good management can be an effective sales tool while bad management can ruin a substantial amount of future sales. The purchaser's attorney sees management as protection for his client's investment and governmental authorities which decide whether or not to permit timesharing resorts to be built or sold in their jurisdiction are wary of a concept which can fall apart without good management. ${ }^{3}$

The essence of good management and the success of the timesharing concept is taking care of people, their money - and their property. Proper management must be well-organized, efficient, economic, and yet, on a personal basis, responsive to the cares and desires of each timeshare purchaser. 4 In a timesharing project where there are a 
number of individual owners and there is about 100 percent occupancy of each unit by several different owners, management can make or break a project. The large number of owners and the short occupancy periods make managing a timesharing project similar to managing a hotel. 5

During the sales period, the developer or club offering the timesharing program will be in charge or will delegate the maintenance of the facility to a management company. The maintenance budget will have already been developed and the developer will usually stick to it throughout his involvement in the resort. The resort will naturally be at its best while it is being shown to prospective buyers or members. 6

In a resort which utilizes the right-to-use method of timesharing in which the resort ownership will eventually revert to the developer or club, the purchasers have no direct voice in deciding who the management company will be. The actual or eventual owner has this authority and responsibility. Hopefully he will realize that it is in his best interest to maintain the resort and facilities at peak condition. Although the purchaser has no voice in management, his complaints will be listened to. Management - has an obligation to satisfy the purchaser's expectations for the continued superior quality of his resort. 7

Under the interval ownership method of timesharing, the purchaser has the privilege and right to have a voice in 
the operation. The specific rights are spelled out in the ownership documents. One vote is provided for each week owned. A proxy is standard and accepted procedure for absentee voting. 8

The interval owners elect a board of directors from within the group of owners, to serve for a period of one year. Officers are elected from the board membership. The interval owner, through the board of directors, selects the management company and the duration of its contract. The management can be a team hired individually by the board or an outside company of specialists. The function of management is maintenance and service, with the guidelines established along with the budget. The management has the freedom to hire and fire its employees or service companies as necessary in order to meet the quality standards set by the board. However it must stay within the guidelines of the annual budget and may not incur greater expense without board approval. The board is required to poll the owners before implementing major changes, and majority vote rules. The board is responsible to the owners and the management must answer to the owners, as represented by the board of directors. ${ }^{9}$

The maintenance fees which are assessed to timeshare buyers are an important consideration for the marketing program and for the operation of a timesharing resort. Developers must find a balance between consumer appeal and 
fiscal restraint, a low maintenance fee may be an attractive marketing tool. However, the impact of a sudden and substantial increase in management fees, which may be necessary when the developer is no longer around to absorb the operating losses, may cause serious legal questions and intense consumer dissatisfaction. ${ }^{10}$ These problems can be avoided by a realistic estimate of resort operating expenses.

Experienced hotel and apartment management personnel should be consulted when preparing a timesharing resort's maintenance budget. Data on apartment and hotel operations should be used for reference but adjustment must be made to correspond to differences in operating characteristics and levels of service. 11

The maintenance budget should include: housekeeping services; utilities; interior and exterior maintenance of the units and buildings; taxes; reservation costs; accounting systems; telephone bills; furniture replacement reserves; amenity upkeep and maintenance; payroll; management fees; insurance against fire, theft, etc., business interruption insurance and other general and administrative expenses. Typically, the most expensive line items are housekeeping - services, utilities, interior maintenance and administrative/ management fees. 12

In order to properly estimate maintenance fees, each timesharing project must project an estimated level of occupancy. Ideally this will involve a realistic estimate 
of the percentage of unit weeks that will be occupied during any given year, assuming that sales expectations are reached. This figure will often range from $40 \%$ to $70 \%$ of the total number of unit weeks available. ${ }^{3}$ The estimate of operating expenses for the entire resort should be divided by the total number of occupied unit weeks expected to be utilized that year. The result is the estimated maintenance fee for each occupied unit week. The developer and eventually the owners' association will have to split the costs of any unsold weeks. 14

Inflation will cause the annual maintenance fee to increase. When projecting future expenses, developers should not forget that if present conditions continue, operating expenses will almost certainly rise. Timeshare unit purchasers should be told that projected expenses are expected to increase because of inflation.

The interval ownership developer and management firm must learn the subtle variations of interval ownership timesharing in order to be in the position to contribute to both the success of the concept and the success of the individual resort. The management company is usually an independent contractor which is initially hired by the developer and retained by the owners' association. Because of the frequency of occupancy changes, the resort should be operated much like a hotel rather than like a whole ownership condominium. It is important for the management firm to 
run the resort like a hotel, but not as a hotel since it should capitalize on the subtle differences. 15

The management firm must realize that it works for the owners' association. It is financially responsible to the association. The funds that the management firm handles do not belong to the firm, but to the owners' association. Therefore the main goal of a successful management firm will be to provide the optimum level of services to the guests, while conserving the funds of the same individuals. The guests are not only clients but are also the employers of the management firm. 16

There are certain management norms which are common to all resort operations and must also be adhered to in the operation of interval ownership resorts. These include:

1. standardized operating practices and procedures

2. supervision and monitoring of services

3. sound fiscal controls

4. sound budgeting process and budget monitoring system

5. physical security and inventory controls

6. sound contracting procedures

7. efficient systems for billings, correspondence, and other recordsit

Additional needs which are common to interval ownership resort management include:

1. Good communication and coordination with marketing efforts of the developer.

2. Good communication and coordination with rental, resale and exchange programs. 
3. Tailored responsiveness to the individual needs of the interval ownership occupant, who is somewhat less dependent upon management than a hotel guest, yet more dependent than a whole ownership condominium resident.

4. Good working relationships with the owners' association, its board of directors, and local governments. 18

There are certain areas within the management of interval ownership condominiums which are particularly unique.

Decision-making is one such area. A good management contract should delineate which decisions can be made by the management firm and those reserved to the association's board of directors. Not only is the management firm guided by the terms of its contract, but also by the condominium Documents and Association By-Laws. However, if possible, any potential conflicts should be worked out in advance. Areas which often cause conflict are: legal and operational relationships with owners; rental policies; working space arrangements; purchasing authority (dollar limits and item categorization); relationships with sales programs; use, if any, of unoccupied or unsold unit weeks; delineation of budget accounting; banking accounts and expense accounts. 19

Another important area is owner, renter and exchanger information. Both management and owners' associations must - communicate regularly with these groups of people. Therefore they should have an accurate system to keep updated information on all owners, rentors or exchangers. Not only is this information significant to the marketing 
entity, but it also is important during billing periods and as occupancy takes place. Simple forms for notification to management of resales, rentals or exchanges etc, should be developed and distributed to all owners. 20

Fiscal controls are also significant. The management firm stands in a fiduciary relationship and must work with the owners' association, especially the treasurer, to arrive at a sound, yet functional approach to handing maintenance fees, per diem, rentals, major and minor purchases, and other income or expense funds. Questions regarding bonding, accounting procedures, bank accounts, collection procedures, disbursement controls, insurance and auditing should all be settled before they become problems. For the protection of both the management firm and the owners' association, once procedures are established, they should be followed. The management firm, along with the owners' association, should create, implement and monitor a realistic budget that is applicable to the needs of interval ownership. 21 Physical security and inventory controls must be designed for the interval ownership facility. Provisions must be made to identify and assess owners, their guests, rentors or exchangers, for damage they may cause. Such assessment is usually provided for in the condominium Documents, but the management firm must have an effective system to quickly verify unit inventories and conditions, and then follow-up with collection procedures. Due to 
the weekly turnover of mit occupants, any lost time or ineffective substantiation can result in dispute and the loss of ability to resover funds. The management staff should be highly visatle and should maintain close personal contact and familiarity with guests and owners in order to enhance the physical security of common areas and to reduce unathorized use of resort facilities by oxtsiders. 22

Management coverage is another unique area. Because an interval ownership resort is primarily operated on a week to week basis, there are opportmities to reduce manpower allocations during certain periods. There periods that requixe increased coverage; such as the times between which the units are vacated and remecupied and cleaning must take place, occupants are chesked in and out, bags are carried, mairotenance needs are talen care of , inventories are taken and funds are collected. Also, if the project does not tave a resident manager, ajegale provisions for fail-safe 24 hour emergency services shauld be developed. 23

Sales and managemext relationships are particularly important to an interval. Dwership resort. ws projects become owner-occupied, yet are still being marketed, conflicts and jurisdictional disputes can arise between sales staff - and management. Office hour coverage by either group, working space arrangements, activities of orer-zealous sales personnel, showing of unoccupied units and saies staff promises which exceed current management ralitiles can all 
cause unnecessary conflict. This harms both sales and management efforts. Good coordination and established procedures are particularly important. 24

The capability to maintain clear, effective and understandable communications between the management firm and unit owners is essential. Form letters specifically designed for particular purposes should be developed for particular purposes and a system for the timely issuance of reoccuring communications should be implemented. This system should include billings, welcome letters, evaluation letters, periodic newsletters and communications requested by the condominium association, including notices for annual meetings, special events and other functions. Written communications which leave no questions in the mind of the recipient are necessary. 25

The interval ownership condominium is basically a resort operation. However, in addition to observing traditionally sound management practices and procedures, the management firm, sales staff and owners' association need to take steps to adequately deal with the differences that exist. Substantial forethought, good supervision and continuous close cooperation and coordination between all parties can help - insure the type of quality service owners and guests expect and at the same time keep management costs and association dues at an acceptable, attractive level. A high level of consumer satisfaction with timeshare resorts will be main- 
trained through competent management. And it is a high

level of consumer satisfaction that will secure the future

of the industry. 26 Also since the continuing value of a

timeshare to a consumer is so closely tied to the quality

of project management, an assurance of ongoing management

is a primary requisite for approval from the various

regulatory agencies. Therefore, the appropriate legal

arrangements for management, its required capabilities,

and its responsibilities should be part of the original

project planning process. Success or failure might

ultimately depend as much on the type and quality of

management as on physical design, location and timesharing

composition. 27

64 
${ }^{1}$ Carl Burlingame, The Buyer's Guide to Resort Timesharing (California, 1981), p. 37 .

2 "Maintenance and operation," The Time sharing Encyclopedia (1979 ed.), vol. 7, p. vii.

3

Ibid., p. viii.

4

Ibid., p. viii.

${ }^{5}$ Alyce Boster, "Marketing the Time-Share Unit," Real Estate Review, (Spring 1975), p. 108 .

${ }^{6}$ Keith W. Trowbridge, Resort Timesharing (New York, Simon and schuster, 1981) p. 102 .

7

Ibid., p. 102 .

8

Ibid., p. 103

9

Ibid., p. 103,104 .

${ }^{10}$ The Time Sharing Encyclopedia, vol. $7, \mathrm{P} . \mathrm{A}-1$.

${ }^{11}$ Ibid., p. A-1.

12 George F. David and Leslie Goldman, "Managing a Time Share Resort," Journal of Property Management, (Sept./oct. 1980), p. 268 .

13 The Time Sharing Encyclopedia, vol. 7, p. A-1.

14 David and Goldman, op. cit., p. 268 .

${ }^{15}$ The Time Sharing Encyclopedia, vol. 7. p. A-5

16 Ibid., p. A-5.

17 Ibid., p. A-5. 
${ }^{18}$ Ibid. , p. A-6.

19 Ibid., p. A-6.

20 Ibid., p. A-6.

${ }^{21}$ Ibid., p. A-7.

22 Ibid., P. A-7.

23 Ibid., P. A-7.

24 Ibid., p. A-8.

25 Ibid., P. A-8.

${ }^{26}$ David and Goldman, op. cit., p. 269. 


\section{Legal}

The legal aspect of resort timesharing is very extensive, and at this point in time has yet to be established definitively. The legal regulations are still being explored and tested. The major areas of regulation are the federal, state and local regulations, and the regulations that control both the developer and the buyer of timesharing.

Since their introduction in this country, timesharing programs have attracted the attention of various state and federal regulators. These regulators faced a major problem in defining what these offerings were; real estate, securities, or something else. This confusion in definition has created a corresponding confusion in regulation. Regulators have approached timesharing programs from their experience in regulating resort housing. Regulators have treated timesharing plans as a variant of the sale of resort housing.

Resort housing sales were largely unregulated until the mid-1960's, at which time two independent regulatory methods were created. Both of these approaches have since developed separately.

One approach was to regulate the sale of resort housing as real estate. At the state level, the offerings were brought under subdivision control laws, and at the federal level. regulation was begun with the passage of the Interstate Land Sales Full Disclosure Act of 1969. This act focused primarily on the sale of recreational lots. The National Association 
of Home Builders was able to obtain provisions which effectively exempted most recreational housing offerings from registration requirements. The federal act, in addition to most state regulation, is structured so mechanically and is so oriented toward real estate that factors necessary for the consumer's analysis of second home rental housing were covered only cursorily if at all. Federal as well as some major states' regulation has been directed at suppressing as many offerings as possible. ${ }^{1}$ Therefore even the most conscientious developers deliberately have structured their offerings to avoid regulation by the federal office of Interstate Land Sales Registration. Developers can escape this regulation either by structuring their offering so that no specific lot or unit is designated as the timeshare or, in the more usual situation, by availing themselves of the exemption under section 1702 of the Interstate Land Sales Act. 2

In 1965 the Securities and Exchange Commission entered the field. It accomplished this not by legislative action but through interpretation of existing law. The sec relied upon voluntary compliance without a more comprehensive definition until 1972. It was against a backdrop of dual - and often conflicting real estate and securities regulations that timesharing programs developed. 3

Since 1974, the policy of the U.S. Securities and Exchange Commission has been to refuse to state an opinion 
concerning an offering of timeshare interests, prior to 1974, the SEC had freely stated its opinion in "no action" position letters with respect to the securities aspects of timeshare offerings. Basically the question addressed by the SEC in these letters was whether the timeshare interest constituted an "investment contract." An investment contract exists when a person gives money to another person or entity in a program constituting a common enterprise, from which he expects to receive profits essentially because of the efforts of that person, entity, or third parties. 4

Examination of the pre-1974 "no action" position letters shows that the SEC considered the following factors as crucial in determining whether a resort timeshare offering may be considered an investment contract, therefore, a security.

1) Whether sales tactics and literature emphasize the investment potential or tax benefits of owning the timeshare interest.

2) Whether the developer or a third party offers to rent the timeshared units for the purchase and whether the purchaser may rent his timeshare to another person.

3) The possibility of the management company being affiliated with the developer.

4) Whether the purchaser may sell his timeshare interest at a price higher than what he originally paid. And in the case of a license or permit for a limited duration, whether the purchaser must sell it for more than the value of his remaining interest based on his original purchase price. 
5) Whether the sales materials include statements that stress that the buyer is purchasing the timeshare for personal use rather than for an investment.

6) Whether the purchaser receives any benefit, direct or indirect, from the operation of the development (such as shares in the profits or losses from the operation of a commercial area like a bar or restaurant within the complex).

Beginning in 1976 , certain resort timeshare offerings were structured as club memberships, in an effort to get around the SEC's refusal to issue no-action letters on timeshare offerings. Such programs gave the club member the right to use the facilities of the club (including living quarters and recreational amenities) for a portion of the year for a certain number of years. 5

The offering allowed resale only to the club, and members acquired no property interest. In order to avoid classification of an offering as a security, counsel frequently structure a prohibition against resale at a profit, This letter, however, does not change the previous sEc position of not issuing such letters on timesharing vacation licenses or similar offerings. This is a narrow distinction, but one which some developers' counsel may find sufficient to avoid securities regulation.

Early in 1976, the Federal Trade Commission announced a study of timesharing plans. During recent years the FTC has aggressively asserted its consumer protection authority. In the land sales area, the FTC has proceeded by filing 
actions and obtaining consent judgments. These judgments create a body of substantive regulation which the commission treats as established case law. Violation of these regulations is viewed as an unfair trade practice. It is probable that the FTC will proceed in the same manner to regulate timeshare offerings.

The present state of regulation of timesharing offerings is one of confusion and uncertainty. The lack of clear federal policy has left regulation of these plans to the states. The states have responded to this situation by adopting a number of regulatory schemes. The lack of consistency has resulted in uncertainty among developers and their counsel.

The emerging state pattern is thus one dictated by "whoever got there first." To sell a timesharing resort offering, a developer must register the offering as a security with the corporation or securities department in oregon, Washington, Alaska, Nevada, Oklahoma, Michigan, Wisconsin, Minnesota, and Illinois; or as real estate with the real estate department in California, Hawaii, Texas, and colorado; and under the consumer protection laws with the attorney general in New York, New Jersey, and Florida. - In some states, such as California, dual registration may be required. 6 
Regulation of offerings by states and with states has increased through the use of the risk capital theory that may be emerging as the most significant securities problem for timeshare developers.

The risk capital theory was first announced by the California supreme court in silver Hills country Club vs. Sobieski. That decision held that club memberships were securities if the member contributed the funds used to develop the club facilities and were "at risk" as to the realization of the benefit sought from the club, even if the benefit sought was not a return on capital or profit. Each year, the "risk capital" theory is reviewed for adoption by courts in more and more states, and timeshare developers can assume that more states will treat timeshare offerings as securities on the basis of the risk-capital theory in the future.

The present view of club membership held by California and other "risk capital" states is that they are not securities for the purpose of state law if the facilities to be used by the members are constructed and improved entirely with capital other than that generated by the sale of memberships and if the income from the sale of memberships is not necessary to repay any loan or make any mortgage or lease payment. 7

The history of resort-housing regulation is a series of attempts to treat such housing as something it really is not 
by distorting existing concepts and statues to accomodate the need for regulation to protect the consumer. The results of this distortion of the regulatory process has been duplicate and triplicate regulation and the imposition or artificial requirements which do not contribute to public protection. This distorted framework has been further strained in attempting to make it cover the new timesharing programs.

One possible solution to the regulatory dilemma is to treat timeshare offerings as securities. This approach offers a number of potential advantages. The securities law conception of fraud, for example, is far broader and offers greater public protection. It also offers better, broader civil remedies. At the state level, the securities regulator has authority to substantially regulate, while real estate laws generally provide for full disclosure. More importantly, however, at both state and federal levels the regulatory approaches employed by securities and real estate regulators are clearly different. The SEC and most state securities administrators view it to be their responsibility to encourage an orderly, honest, and active market in securities. On the other hand, the office of Interstate Land sales registration under its first administrator appeared to view its function to be that of an antagonist of the industry it was regulating. While this attitude did not filter down to most state regulators, 
neither did a philosophy of responsibility for a healthy market. In addition, the major arawback of securities regulation, is the requirement of broker/dealer qualification in the sale of resort-housing securities, and is gradually disappearing. 8

It would be possible to create a single, perhaps hybrid, scheme of regulation with which the resort-housing industry could live; perhaps registration as securities with regulation of sales personnel under the real estate laws. The basic problem with this approach is that it ignores reality and strains the fundamental concepts of the laws being used to protect the public. Each statutory scheme carries with it a regulatory pattern which is hard, if not impossible, for regulators to apply to unrelated situations. 9

There is a tendency for inappropriate requirements to be carried along with the more general substantive provisions of a regulatory scheme and there is a trend to recognize the essential character of condominium securities as real estate to be regulated only by the real estate regulator. If the legislature adopted the anti-fraud concepts and remedies of securities laws, the legislature will have fashioned the conceptually most appropriate regulatory - scheme for condominium securities.

TSO programs are conceptually and factually different from other types of timesharing plans. Tso is a form of tenancy in common in a condominium. Therefore, Tso programs 
should be regulated under the same regulatory scheme applicable to the sale of whole condominium units.

This is not the case with the right-to-use programs, vacation leases and licenses. Just as the trend in condominium regulation is to base the regulation on what the buyer conceives he is buying, which is real estate, the proper regulation of right-to-use programs should be based on what the consumer perceives he is purchasing. The customer sees himself as buying a long-term prepaid vacation. Customers do not see themselves as purchasing securities. They would not go to a security broker/dealer to make such purchases. Although a long-term prepaid vacation can be viewed as a leasehold interest in real estate, customers do not perceive themselves to be purchasing real estate and would not return to the real estate broker who sold them their houses to make such purchases. Attempts to force timesharing programs into either of these patterns does violence to both the actual situation and the buyer's perception. 10

Furthermore, it is unlikely that purchasers of right-touse offerings would compare such purchases with investments in AT\&T or U.S. Steel, that is, consider them to be part of their investment portfolio. They are far more likely to compare such purchases with purchases of cabin cruisers, fur coats, or foreign sports cars. These purchasers are likely to have rejected the purchase of second home real 
estate in favor of pre-paid vacations because timesharing plans will entail none of the responsibilities of real estate ownership. If prospective purchasers seek the advice of any of their advisors, they are more likely to turn to their travel agents.

If timesharing programs are not securities or real estate, but need to be regulated to protect the consumer, then the one regulatory scheme which is appropriate already exists under state consumer protection laws and the regulations of the Federal Trade Commission.

The only satisfactory alternative is the creation of an entirely new bureaucratic scheme. Neither the dimension of the problem nor the public need justify a new bureaucracy. 1

Federal and state consumer protection procedures are particularly suited to regulation of the wide variety of programs which are found in right-to-use types of timesharing. Whether or not further statutory authority is necessary depends upon the particular statue involved. Generally, however, the regulatory procedure should take the following form. After appropriate public hearings, the regulator should adopt regulations defining unfair practices. These regulations should outline required disclosures to be - made before the sale. Either by statute or regulation, the offeror should be prohibited from failing to state material facts or from failing to state facts which under the circumstances tend to make the' facts stated misleading, 
which is contained in the standard securities fraud definition, in Rule 106-5. The regulations should also contain substantive requirements on mortgage subordination or, in the alternative, fund escrowing. While the regulator should be given the power to seek injunctive relief, the principal deterrents should be civil remedies such as double or triple damages, contract cancellation and attorney fees. Although a notice of offering might be required, no complex registration process, with its attendent increase in government costs, should be included. Rather, the burden of establishing compliance should be placed on the developer. Finally, the concepts of securities laws should apply to legal, accounting, and sales personnel involved in the offering. Such a regulatory framework would offer full protection to the purchasers of timesharing offerings, 12

This regulatory process would limit the tendency of inapplicable concepts and procedures to be carried over such as would result from the application of either securities or real estate laws. The sales personnel would not have to be securities brokers/dealers when neither the seller nor the buyer perceives that he is dealing in securities; nor would such personnel have to be licensed real estate brokers when neither the seller nor the buyer believes that he is dealing in real estate. None of the restraints properly imposed on the sale of securities and real estate would be imposed artificially on the sale of 
long-term prepaid vacations. Instead, in addition to the developer's sales personnel, travel agents who are trained and qualified to compare vacation opportunities could engage in marketing these prepaid vacations. 13

Over the past decade, securities and real estate law have been distorted to accomodate the protection of buyers of various types of resort housing. More recently, these same laws have again been strained to provide such protection to the purchasers of timesharing offerings. Regulators providing this protection are now having second thoughts as to the validity and priority of this protection in light of the basic functions for which their agencies were created. After ten years, legislators and regulators are returning to the basics. They are recognizing that condominiums, whether heretofore treated as securities or not, should be regulated as the buyers perceive them: as real estate. As part of this process, the broader antifraud and civil remedies of securities law, which origianlly justified securities regulation of resort housing, are being brought into real estate regulation.

A similar return to basic theory and public perception should be the foundation of timesharing regulation. Where - the buyer acquires a real estate interest in a condominium, as in the TSO programs, regulation should be part of the general condominium regulation process. On the other hand, timesharing offerings such as vacation leases and licenses, 
which actually are and are perceived by both sellers and purchasers to be long-term prepaid vacations, should not be regulated as either securities or real estate. Instead, they should be regulated under the consumer protection laws as what they are: luxuries in the form of prepaid vacations. 14 
"Regulation of Resort Timesharing." The Time sharing Encyclopedia (1979 ed.), vol, 2, p. A-l.

${ }^{2}$ David G. Ellsworth and James D. Prendergast, "Securities Maze Awaits Resort Time-Share Offerings," Real Estate Review, (Spring 1980), p. 60 .

${ }^{3}$ The Time Sharing Encyclopedia, vol 2., p. A-2.

${ }^{4}$ Ellsworth and Prendergast, op. cit., p. 62.

${ }^{5}$ Ibid., p. 60

${ }^{6}$ The Time Sharing Encyclopedia, vol. 2, p. A-4.

${ }^{7}$ Ellsworth and Prendergast, op. cit., p. 62 .

${ }^{8}$ The Time Sharing Encyclopedia, vol. 2, p. A-7.

${ }^{9}$ Ibid., p. A-8.

$10_{\text {Ibid. }}$, p. A-9.

${ }^{11}$ Ibid., p. A-10.

12 Ibid., P. A-10.

${ }^{13}$ Ibid., P. A-10.

14 Ibid., p. A-11. 
As with any type of resort development, it is difficult to obtain financing for a timesharing project. Many of the early timesharing projects which failed did so because of the assumption that sufficient financing could be secured and because of an underestimation of the amount of upfront cash needed. ${ }^{I}$ Because timesharing is a relatively new concept, it is often difficult for a developer to present a successful track record in such projects. The situation is further complicated by the tight money and economic problems that our country has encountered in the last several years. Although a number of projects have shown that a certain amount of timesharing sales may be made on an all-cash basis, there is no dispute that no long-range and broad-based marketing program can proceed without financing. 2

obtaining financing, either construction or takeout, for a timesharing project has been difficult because lenders are not yet familiar with the unique characteristics of the timeshare concept. While a timeshare property has been considered real estate, it has certain features which are not generally associated with real estate. For example, the real property itself may have as many as fifty different owners and the value of the timeshare is based not only on the real estate, but also on the specific time period owned. $^{3}$ These two characteristics cause confusion with 
regard to traditional appraisal and foreclosure techniques. Lenders are reluctant to offer takeout financing on a specific period of time such as "two weeks in December", which they find difficult to appraise, especially since they are uncertain as to the effectiveness of foreclosure if this becomes necessary. To eliminate the foreclosure problem, developers often must agree to repurchase the timeshares of any owner who fails to meet his financial obligations. 4

Although there are difficulties, it is possible to obtain financing for timesharing projects. It is necessary to find a lender who is willing to alter traditional techniques and methods in order to fit the characteristics of an untraditional product. Indications are that once the timesharing concept is understood and the project and shares are properly appraised, lenders will judge a timesharing development just as any other - on the basis of project quality, feasibility, marketability and developer strength. 5

The financial structure of each timesharing project is unique. The structures vary within the industry from conversion projects and resort additions to projects started - from scratch. Financing should be tailored to the specific project.

Capital requirements in timesharing developments, like in any development, depend upon the extent of outside 
financing available to the developer. Ideally, financing of a timeshared project calls for a source of financing for the end loans (loans to the ultimate consumer to purchase his timeshared unit), and release provisions allowing removal of the encumbrance of the blanket construction or purchase money mortgage on a per time period basis. 6 In the absence of both types of financing, the developer must use a considerable amount of his own cash at the beginning of the project, causing a severe cash flow deficit.

The potential timesharing developer should be aware that, without well-structured outside financing, his upfront capital requirements, in relation to the size of the project, may be large. There are many approaches to financing which can be taken. While some approaches may help to reduce up-front expenditures, no approach to financing will make these expenditures disappear. The developer will still be faced with the probability of maintaining escrows until there are sufficient purchasers in each unit to carry the mortgage on that unit. Until that point is reached in each unit, marketing dollars, sales commissions and other expenses of running the operation must come out of the developer's own funds. 7

The increased sales price on a timeshared project can give the impression that initial capital requirements are lower than in a standard project. However, the opposite is often true. Therefore it is extremely important for the developer to carefully examine capital requirements when 
analyzing any potential timesharing projects. Also, outside financing should not be counted on unless definite committments and arrangements have been made. 8

The term "end loans" refers to those loans which finance the actual time period by a consumer. This may be done by third party financing supplied by a finance institution, or by purchase money notes taken back by the developer upon sale. The developer's purchase money notes may be discounted to a finance institution. 9

It is very likely that the key to over-all financing of a timeshared resort is having a source for end loan financing. 10 Many construction lenders will condition their loans upon the developer obtaining end loan commitment because they feel that end loans are necessary in order for the construction loan to be ultimately satisfied. Without end loans it becomes difficult to find a means of releasing units from the construction loan and thereby convey the time period to the purchaser. 11

It is advantageous for the developer to have a source for discounting the notes he holds because in this way, enough money would be available to release a unit, pay his marketing costs and sales commissions and allow him to realize his profit at once, rather than waiting until the loan is paid off, to do so. 12

Another advantage of having an outside source of financing the purchasers' notes is that the terms will 
generally be more liberal than those given by the developer. Because of his cash flow requirements, the developer will generally require a much larger down payment applied against his release of the unit. In this way he can pay off the notes as soon as possible. The lower the down payment and monthly payments, the more attractive the purchase of the timeshared unit will look when compared with expenditures for vacations, especially in the earlier years. 13

Ideally a lender will be committed to take all end loans which the developer turns over. However, in practice; many lenders will look at the credit worthiness of each specific buyer, using similar qualifying procedures as those employed for other consumer financing. Many state usury laws permit substantially higher interest rates for such consumer installment loans. 14 other lenders may treat timesharing end loan financing much the same as they do sales of traditional shelter projects. Naturally the type of offering involved, whether it be a timesharing condominium, a vacation license or lease etc., will be a key factor in determining a lender's approach. 15

To date, the majority of end-purchaser financing has been obtained directly through the developer/marketer or through financial institutions located in the community where the timeshare project is located. Recently, several large commercial banks and finance companies have entered into timeshare financing on a nationwide scale. These 
institutions include Citibank, Mellon, Aetna Business Credit, Inc., General Electric credit Corporation, and security Pacific Finance corporation, among others, 16

Construction financing for projects to be built are expensive undertakings. Lenders have recognized that high land costs in resort areas along with high unit costs of materials, furnishings and the development and construction of on-site amenities require high levels of initial equity in the form of cash up front and portions of the proceeds of each interval purchase price to retire construction debt. While conversions of existing resorts may require less cash equity. But a reasonable level of initial cash equity is needed for unit construction/conversion. 17

Construction and development loans may be made secured by mortages, personal and corporate guarantees, and other collateral. Construction lending agreements should be tailored to ensure not only the completion of the physical units in accordance with plans and specifications but also should tie in with a project's marketing schedule so that sales can be used to retire development financing. Because the timesharing concept involves an accommodation for future use, many timeshare developments presell their units and obtain construction funding as sales require. 18

The ideal construction financing would include release provisions per time period. In this way a release price would be established for each time period allowing the developer to release that particular time period and deed to 
the purchaser. This, along with a source for financing the end loans, would constitute the most desirable total financing plan for the development. 19

The ideal financing formula is a construction mortgage or, for an existing facility, a purchase money mortgage which will fractionalize into end loans based on per time period releases. Such an ideal formula may not be obtainable to many developers at this time. 20

The next most desirable financing plan would include a per unit release, with proceeds escrowed on each time unit sold within the particular unit until a certain number is released, together with a source of end loan financing. In this way the lender does not have to get involved in the actual timesharing attributes of the project. Where releases from an underlying mortgage are not readily obtainable, vacation licenses and vacation leases can be used. Assuming that this method can be implemented under local law, its limitations relate mainly to its marketability. 21 Where tenancy in common timesharing is utilized, a master mortgage may be put on the unit, with joint and multiple liability among all the holders of interest in time periods. The main drawback to this approach is that, - in the event of a default by one of the holders of a time period, the other owners would remain liable for the defaulting owner's share of the mortgage payments. 22 
With either tenancy in common or interval timesharing, financing may consist of a contract for a deed containing a provision would bar early payoff of the balance, and a subsequent duty on the part of the developer to convey title prior to the time the underlying mortgage is paid off. However there are some marketing drawbacks to this method. Also, since the method requires an estimate as to when the underlying mortgage would be paid off, if the estimate varies from the actualities of the situation and the terms in the contract for the deed requiring the passing of title are reached prior to payoff of the mortgage, the developer is in trouble. 23

Another approach to the financing dilemma is to require that all purchasers pay cash for their time periods. Such cash proceeds would be escrowed until the time that sufficient amounts have been built up to release each unit. This method assumes that a construction mortgage exists with release clauses allowing per unit releases. This method is applicable if the per time period cost is low enough and the economic strata of the market appealed to is high enough. A review of several interval ownership projects shows that as high as 75 percent of sales were in cash. 24

The possibilities for working out financing are limited only by the ingenuity of the developer and the receptivity of the lender. With proper planning, imaginative approaches and a lender who is willing to listen, a workable 
financing formula which will satisfy the needs of both the developer and the lender can be achieved. 25 
"Financing," The Time Sharing Encyclopedia (1979 ed.) vol. 5, p. vii.

2

Ibid., p. vii.

3Alyce Boster, "Marketing the Time-Share Unit," Real Estate Review, (Spring 1975) p. 107 .

${ }^{4}$ Ibid., p. 107

5 Ibid., p. 107

${ }^{6}$ The Timesharing Encyclopedia, vol, 5, p. A-1.

${ }^{7}$ Ibid., p. A-2.

${ }^{8}$ Ibid., $\mathrm{p} . \mathrm{A}-2$.

${ }^{9}$ Ibid., p. A-7.

$10^{\text {Ibid. }}, \mathrm{p} \cdot \mathrm{A}-7$.

${ }^{I I}$ Ibid., p. A-7.

12 Ibid., p. A-7.

13 Ibid., p. A-8.

14 Ibid. , p. A-8.

${ }^{15}$ Ibid., p. A-8.

16 Natalie Gerardi, "Update on Timesharing," House and Home, (March 1976), p. 33 .

17 Ibid., p. 33

18 Ibid., p. 33

19 The Time Sharing Encyclopedia, vol. 5, p, A-3. 
${ }^{20}$ Ibid., p. A-9.

${ }^{21}$ Ibid., p. A-9.

22 Ibid., P. A-9.

23 Ibid., p. A-9.

24 Ibid., p. A-10.

25 Ibid., p. A-10. 
Even though relatively inexpensive compared to other types of recreational real property, the majority of timeshare buyers still finance their purchase rather than paying cash for it (Table IV-F). In the 1980 survey, over twothirds ( 67.6 percent) of the respondents financed, which is almost exactly the same as in the 1978 survey (68.0 percent). Average percent down payment in the 1980 survey was 15.7 percent (compared to 16.1 percent in 1978), and average years for loan payback was 6.0 (exactly the same as in 1978). Due to the fact that the data are historical in nature rather than reflective only of current purchases, the average interest rate was found to be only 11.3 percent. It is important to note that only 37.4 percent of the respondents stated they would have purchased their timeshare without the availability of financing. Some 43.5 percent said they would not have made the purchase and the remaining 19. I percent said they did not know (Table IV-G). In regard to source of financing, about one-half $(47.0$ percent) obtained it through the company from which they bought their timeshare (Table IV-H). The next most frequently checked sources were "lending institution in the community in which the timeshare project is located" with 29.3 percent, and "other lending institution" with 12.0 percent. Only 7.4 percent checked "lending institution in home community" which indicates that timeshare market is 
still a long way from being popularly recognized as a viable product amongst most local financial communities. In regard to type of buyer financing their timeshare, some very significant differences, are noted below:

1. Age of household head. Younger buyers are much more likely to finance their purchase. For example, about 82 percent of those under $35 \mathrm{fi-}$ nanced, while this proportion was only 55.6 percent for those respondents between 55 and 64 years, and only 38.9 percent for those over 65 . Household income. Financing is frequent amongst all income levels although it significantly decreases as income increases. While about 73 percent of respondents having incomes under $\$ 25,000$ financed their purchase, this proportion was only about 55 percent for those with incomes over $\$ 50,000$ (which is still quite high). Average purchase price. Average weekly purchase price of financed units was slightly higher than for those paid for by cash: $\$ 3,978$ compared to $\$ 3,825$

*Source: Richard L. Ragatz for the Resort Timesharing Council of the American Land Development Association, 1979 . 
Cash

Financed

Total

Average Size

Average percent down payment

Average percent interest

Average years for payback

$$
\begin{gathered}
32.4 \\
67.6 \\
100.0 \\
9,545 \\
15.7 \% \\
11.3 \% \\
6.0
\end{gathered}
$$$$
32.0
$$$$
\frac{68.0}{100.0}
$$$$
1,564
$$$$
16.1 \%
$$$$
\mathrm{n} \cdot \mathrm{a} \text {. }
$$$$
6.0
$$

Would Have Purchased If No

Financing Available

$$
\begin{aligned}
& \text { Yes } \\
& \text { No } \\
& \text { Don't Know } \\
& \text { Total } \\
& \text { Sample size }
\end{aligned}
$$

Main source of Financing

Company from which bought timeshare

Lending institution in home community

Lending institution in timesharing community

other lending institution

Private source

other

Total

Sample size

37.4
43.5
19.1
$\begin{aligned} & 100.0 \\ & 9.178\end{aligned}$

47.0

n.a.

7.4

29.3

12.0

2.0

$\frac{2.3}{100.0}$

6,590

*Source: Richard L. Ragatz for the Resort Timesharing Council of the American Land Development Association, 1979 . 
A. Age of Household Head

$\begin{array}{llll}\text { Under } 25 & 14.7 & 85.3 & 100.0 \\ 25 \text { to } 34 & 18.7 & 81.3 & 100.0 \\ 35 \text { to } 44 & 27.5 & 72.5 & 100.0 \\ 45 \text { to } 54 & 34.0 & 66.0 & 100.0 \\ 55 \text { to } 64 & 44.4 & 55.6 & 100.0 \\ 65 \text { or older } & 61.1 & 38.9 & 100.0\end{array}$

B. Household Income

Under $\$ 15,000$

$\$ 15,000$ to $\$ 19,999$

$\$ 20,000$ to $\$ 24,999$

$\$ 25,000$ to $\$ 29,000$

$\$ 30,000$ to $\$ 39,000$

$\$ 40,000$ to $\$ 49,999$

$\$ 50,000$ to $\$ 99,999$

$\$ 100,000$ or more
29.8

26.0

26.9

29.7

31.8

32.4

40.7

46.3
72.2

74.0

73.1

70.3

68.2

67.6

59.3

53.7

C. Average Purchase Price $\$ 3,825 \quad \$ 3,978$

\footnotetext{
*Source: Richard L. Ragatz for the Resort Timesharing Council of the American Land Development Association, 1979 .
} 
Exchange entails trading one's own interval for equal time at another time at another resort or for a different time at one's own resort. Each trade is on a one-time basis. A timesharing exchange service is essentially a reservation network which assists timeshare owners in exchanging their time periods with other timeshare owners. ${ }^{l}$ Exchange services have played a major role in the consumer acceptance of timesharing, by eliminating the consumer's doubts about committing himself to a single resort and time period for an extended length of time. ${ }^{2}$ For many purchasers the opportunity to exchange accommodations and time periods enhances the flexibility and therefore the attractiveness of timeshare ownership. The opportunity to participate in an exchange program has been given as one of the most important reasons for purchasing a timeshare. over $70 \%$ of buyers list this reason as their primary motivation. Over $90 \%$ of interval owners are members of one of the two independent exchange companies, and others participate in internal programs. Over one-third of the existing owners have requested a trade and it is reported that over $80 \%$ receive a satisfactory trade. 3

At this time there are three basic types of exchange services. These include trading networks, internal exchange services and external exchange services. Trading networks include exchanges of resort and vacation units and time- 
shares through private arrangements by individual owners. The builders and sellers of the condominiums and timeshares etc. are not included. 4 Internal exchange services are operated by individual developers or companies that have facilities at different locations. Exchange privileges are offered to members at the various resorts owned by the common operator. 5 External exchange services are the most common. An independent company lists available accommodations and coordinates trades. Developers pay a fee to list their resorts and owners pay a membership fee and a trading fee which is refundable if the trade is not confirmed. Individual memberships are limited to purchasers at affiliated resorts. 6

A timesharing developer must become a member of one of the external exchange services in order to make the exchange service available to the owners of its units. Once the resort passes an inspection and the developer pays a fee, it can be listed in the exchange service's directory of member resorts. Buyers of time periods in the resort may then become individual members of the exchange service by paying annual membership dues and will be eligible to utilize the exchange service to make trades. 7

The exchange service companies utilize computers to arrange trades among large numbers of participants. If there are no units available at a requested resort, alternatives are usually suggested. The exchange services 
enable timeshare owners to experience different resort or a different time period in resorts witb a valabilities. A person may reject alternatives until he finds one that is appealing. There is no charge unless an exchange is confirmed. 8

An individual who wishes to exchange his time period submits an exchange application to the excinage service company that his resort and he are a member of. In order to process an exchange the trade request must include the following information: three desired vacation areas in order of priority, specific resorts requested, dates preferred and possible alternative dates, the number of adults and children in the party, the sleeping capacity needed (not to exceed the number in the individual's unit) and the name of the individual's resort, unjt number and week number offered for exchange. 9 It is necessary to notify the exchange companies of ore ${ }^{x}$ desire to trade at least sixty days before one's home resort vacation time or the date being requested, whichever romes first. 10

Although a number of new exchage companies have been formed lately, there are still only two major exchange companies. Resort Condominiums Internation (RCI), which - was originally organized in 1974 to osist comdominium developers in selling new units and to assits owners in exchanging their wholly owned condominiums, found itself in the middle of the interval resort sharing industry as 
of July 1981, RCI had more than 130,000 members at over 480 resorts located in thirty countries. While this includes both wholly owned and interval types, about 400 of these resorts have a majority of interval units, which add up to approximately 12,000 apartments. 11 Interval International (I.I.), founded in 1976, was the second major exchange company to be developed. According to the latest figures, Interval International has exchange agreements with approximately 270 resorts which specialize in timesharing in thirty countries. Their listings include about 11,200 interval apartments. 12 while both Resort Condominiums International and Interval International are extremely efficient and capable, the two exchange companies use different approaches to facilitate exchanges.

Resort Condominiums International charges its members $\$ 42.00$ as an annual membership fee. As long as the buyer joins at the time of purchase he is not subject to an additional $\$ 100$ membership fee. The fee per trade is $\$ 38.00$ per each week requested. RCI uses a "space bank" concept which is similar in operation to a checking account. An owner places his time period into a "bank" of time periods made up of all the time periods offered by members desiring - exchanges. A depositor may withdraw a similar amount of time as he deposits. Deposits can be made at the same time or ahead of withdrawals. A depositor may use the time he withdraws even if his spacebanked interval is not 
used and he may also use his own spacebanked time if it is not used by another member. If a member can not use his own interval in a given year he can accrue his time to the next year, as long as another member uses his interval. In order to assure equitable exchanges, RCI divides its members' intervals into three categories: red represents the period of greatest demand, white represents the time period of average demand and blue represents that of lesser demand. A member must exchange within the category in which his own interval falls. Also, an exchange must be to a unit having the same occupancy as the one the member owns and deposits into the spacebank. RCI requires its member resorts to set aside units strictly for use by exchange members, in order to increase its supply of exchange availabilities. 13

Interval International limits its individual memberships to owners at affiliated resorts who join within ninety days of their timeshare purchase. If an individual does not join within this time period, he is not eligible for membership for another four years. The annual membership fee is $\$ 39$ and the fee per trip transaction is $\$ 39$, regardless of how many weeks are involved at one time. ${ }^{14}$ This fee is refunded if the trade is not confirmed. Interval International uses an "interval selection method." This method is based on the theory of supply and demand. A member must put his interval up for exchange and request a 
a trade at the same time. Once a member receives a confirmed trade he relinquishes his use rights to his own interval for that year. While there is no accrual system, exchanges can be made within the twelve-month membership period, rather than within a calendar year basis. Interval International does not categorize unit weeks into priority divisions so members may request any time or place listed in the company's directory. However they may not request more sleeping capacity than they are giving up in trade. Also the company warns its members not to expect to be able to trade low demand times for high demand times. In order to enlarge its supply of trading availabilities, Interval International arranges for extra space from the unsold inventory of its member resorts. However, unlike with RCI, this is not a condition of a resorts affiliation with the company. 15

Exchange programs are attractive for many reasons. In particular, external exchange serves are popular because they offer their members the maximum flexibility, variety of choices and the help of the exchange service in making arrangements. The external exchange services now offer such features as rental car discounts, travel insurance policies, currency exchange information, emergency cash forwarding, coupon books and travel arrangement services etc. 16 Exchange programs are particularly advantageous to timeshare buyers who cannot predict their vacation times, year after year; who do not wish to vacation at the same place each 
year; whose vacation patterns are subject to change and/or to those affected by job transfers. 17

It is important for a timeshare buyer to purchase at the resort and during the season which best suits his needs. Exchanges can not be guaranteed. Each resort must pass a sixty-five point inspection which covers everything from the ambiance and the interior and exterior of the facilities to the financial security of the developer, before it is accepted by the exchange company. 18 However once in awhile a resort which does not make it financially or which does not have strong exchange appeal manages to become affiliated with an exchange service. Trading can then become a disappointment. 19 while exchange programs have many advantages, it is necessary for exchange services to make promises that they cannot keep and for developers and their sales persons not to make promises of potential exchange fulfillment that can not be realistically kept. A buyer should purchase in a resort that has intrinsic appeal; the purchase should not depend totally on the concept of exchange. 20 
${ }^{1}$ Thomas J. Davis, Jr., "Time-Sharing Exchange Networks," Real Estate Review, (Fall 1978), p. 43.

Ibid., p. 43 .

${ }^{3}$ Dennis G. Dunn, "Lending to the Resort Timesharing Industry," The Journal of Commercial Bank Lending,

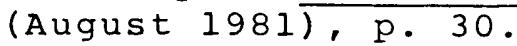

4 The American Land Development Association, Resort Timesharing: A Consumer's Guide (Washington, D.C. 1980), p. 10 .

${ }^{5}$ Dunn, op. cit., p. 30 .

6 American Land Development Association, Resort Timesharing Fact sheet, (Washington, D.C., 1982), p. 5 .

7 Davis, op. cit., p. 43 .

${ }^{8}$ Keith W. Trowbriage, "Resort Timesharing" (New York. Simon and Schuster, 1981), p. 114 .

9 Ibid., p. 115 .

$10_{\text {Ibid. }}$ p. 115 .

${ }^{11}$ Ibid. , p. 116

12 Ibid., p. 116

13 Carl Borlingame, The Buyers Guide to Resort Timesharing (California, 1981), p. 47 .

14 Interval Internationa, Inc., Vacation Planner and Directory 1981-1982 (Miami, Florida, 1981), p. 1 .

${ }^{15}$ Burlingame, ㅇp. cit., p. 45 .

${ }^{16}$ Trowbridge, op. cit., p. 129. 
17 The American Land Development Association, Resort Timesharing, p. 11 .

18 Trowbridge, op. cit., p. 130.

19 Ibid., p. 130 .

${ }^{20}$ Davis, op.cit., p. 45 . 


\section{*VI THE EXCHANGE PRIVILEGE}

\section{Exchange Privilege Belong To}

Popularity of the exchange privilege in the resort timesharing market is emphasized in that 93.2 percent of the respondents were members of one of the exchange companies (Table VIII-A). Results are biased toward Resort Condominiums International (with 78.5 percent of the respondents) since most sponsoring companies belonged to this organization rather than Interval International (with 12.4 percent), or any of the other, smaller exchange organizations. The actual split for all timeshare owners in the United states according to exchange company is considerably more even than portrayed in this survey; however, it is known that RCI currently does have the majority of the total.

only 1.6 percent of the respondents belonged to both RCI and II and 0.7 percent said they belonged to some other exchange company.

Whether Have Requested Trade

over one-third ( 36.7 percent) of the respondents had already requested a trade, which was slightly higher than the 32.9 percent in 1978 (Table VIII-B).

The following paragraphs further describe the type of respondent who has requested a trade.

1. Length of ownership (Table A-15-A). A definite relationship exists between use of the exchange privilege and how long a family has owned their 
timeshare. For instance, only about 20

percent of those owning for less than

one year had requested a trade whereas

this proportion was 45.7 percent for those owning for two years and 60.9 percent for those owning for four or more years. Such findings again emphasize the definite advantage of flexibility in vacations over time offered by the timeshare market in cooperation with the exchange privilege.

2. Average purchase price (Table A-I5-C). Related to the findings concerning size of unit is the fact that owners of less expensive units are more likely to have requested a trade. The average weekly purchase price of units owned by respondents who had requested a trade was $\$ 3,609$ compared to $\$ 4,110$ for those who had not.

3. Location of timeshare unit (Table A-15-G) Persons owning timeshares in locations traditionally considered prime destination resort areas (e.g., Hawaii, the Caribbean, Mexico, and the west Coast) were much less likely to have requested a trade than were those in some other areas (especially the Mid-Atlantic (including New Jersey, New 
York, and Pennsylvania, New England and North Central regions.

4. Satisfaction with timeshare purchase (Table A-I5-H). More satisfied respondents tended to have less frequently requested a trade: about 35 percent for those who expressed satisfaction and 45 percent for those who expressed some dissatisfaction.

5. Type of construction (Table A-I5-I). As with average weekly purchase price, a correlation exists between type of construction and request for trade. For example, 47.0 percent of the respondents who own a timeshare in a project converted from a hotel/motel with minor renovations had requested a trade, whereas this proportion was only about 35 percent for all other respondents. It thus appears that many people are buying very small timeshares at relatively low prices in non-prime locations with the intent being to trade their unit for a more desirable one in a more attractive location.

\section{Trades Requested}

For those respondents who had requested a trade, about one-half ( 48.9 percent) had just made one request as shown in Table VIII-C. About one-quarter (23.8 percent) had made three or more requests with the average being 1.9 . 
Some 20.5 percent of the respondents had requested a trade without having one confirmed as shown in Table VII-D. For some of these respondents, the request was probably being processed during time of the survey, while for others, a satisfactory alternative location may not have been offered by the exchange company. While 23.8 percent of the respondents had made requests for three or more trades, only 13.6 percent had three or more requests confirmed. Type of Trade Received

Table VIII-E shows that 74.1 percent of the respondents had received a trade representing either their own first choice ( 35.8 percent) or their own alternate choice ( 38.3 percent). This represents a significant improvement from the 1978 survey when the combined proportion was only 57.9 percent. The remaining 26.0 percent in the 1980 survey had received a trade which represented the exchange company's alternate (compared to 42.1 percent in 1978).

Satisfaction with Exchange

For respondents who had already participated in the exchange privilege, a very high 89.6 percent said they were either "very satisfied" (51.9 percent) or "satisfied" ( 37.7 percent) with their trade. This is almost exactly the same proportion as in the 1978 survey (90.7 percent) as shown in Table VIII-F. It should be noted that the sample size for this question represents over 2,000 persons, which substantiates the validity of the data. 
*Source: Richard L, Ragatz for the Resort Timesharing Council of the American Land Development Association, 1979 .

Fairness of Exchange Representation

In Table VIII-H, it is found that 14.3 percent of the respondents did not feel the exchange privilege was fairly represented by the person from whom they bought their timeshare. In other words, it appears a few people thought the exchange opportunity offered more than it actually did.

No real significant variations occur amongst the various age, education, and income levels in regard to this variable. Persons expressing the greatest frequency of negative answers were the oldest respondents (over 65), and the lowest income respondents (less than $\$ 15,000$ ). Even with these groups, the vast majority still felt the exchange privilege was fairly represented.

*Future Use of Exchange Privilege

In the 1980 survey, 28.3 percent of the respondents stated they intend to use the exchange privilege every year as compared to 39.5 percent in the 1978 survey (Table VIII-G). Some 13.5 percent in 1980 said they plan to use it infrequently or never whereas this rate was only 6.5 percent in 1978 . Such changes probably are due to the increasing quality of recent timeshare projects and more consumers' satisfaction with their own purchases. 
The type of respondents who expect to use the exchange privilege most frequently in the future are those who:

1. purchased the smallest units, especially studios $(\mathrm{Table} A-18-\mathrm{A})$

2. purchased the least expensive units (Table $A-18-B$ )

3. live within 25 miles of their timeshare purchase and who apparently bought for investment/resale or simply for the opportunity to participate in the exchange system. The rate of "every year" responses was more than twice as high amongst buyers living within 25 miles of their timeshare than amongst those living more than 1,000 miles away (Table A-18-C).

4. are younger, especially under 35 (Table A-18-D)

5. have lower incomes and probably purchased less expensive units (Table A-18-E)

6. purchased timeshares in areas not traditionally reputed to be major destination resort regions, e.g., South Central, Mid-Atlantic, North Central, etc. Respondents who have purchased timeshares in Hawaii, Florida, Mexico, and the Caribbean anticipate to do the least exchanging in the future (Table A-18-F).

*Source: Richard L. Ragatz for the Resort Timesharing Council of the American Land Development Association, 1979. 
A. Exchange System Belong To

Interval International

\begin{tabular}{r}
12.4 \\
78.5 \\
1.6 \\
0.7 \\
6.8 \\
\hline 100.0 \\
9,573
\end{tabular}

Total

Sample size

Resort Condomin
Both II and RCI

Other

None

B. Have Requested Trade

Yes
No

Total

Sample size

C. Number of Trades Requested

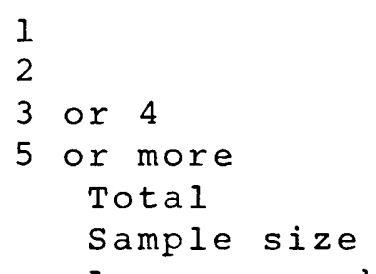

Average number

D. Number of Trades Confirmed

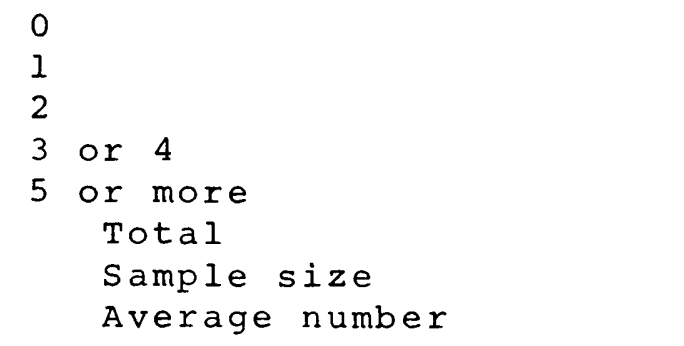

\begin{tabular}{rr}
36.7 & 32.9 \\
63.3 & 67.1 \\
\hline 100.0 & $\frac{60.0}{100.0}$ \\
9,446 & 1,564
\end{tabular}

48.9

64.2

27.4

19.5

25.8

8.2

$\frac{4.3}{100.0}$

3,471

1.9

$\frac{1.8}{100.0}$

512

n.a. 
E. Type of Trade Received

Your lst choice

Your alternative choice

Exchange company's

alternative choice

Total

Sample size

F. Satisfaction with Exchange

Very satisfied

Satisfied

Dissatisfied

Total

Sample size

$$
\begin{array}{r}
35.8 \\
38.3 \\
26.0 \\
\\
\hline 100.0 \\
2,441
\end{array}
$$

(combined)

42.1

$\overline{100.0}$

323

\begin{tabular}{rr}
51.9 & 60.0 \\
37.7 & 30.7 \\
10.4 & 9.3 \\
\hline 100.0 & 100.0 \\
2.253 & 270
\end{tabular}

G. Future Use of Exchange Privilege

Every year or more

Every other year

Every third year

Infrequently

Never

Don't know

Total

Sample size

\begin{tabular}{rc}
28.3 & 39.5 \\
22.9 & 20.2 \\
5.2 & 5.2 \\
10.9 & $(6.5)$ \\
2.6 & $($ combined) \\
30.0 & $\frac{28.6}{100.0}$ \\
\hline 100.0 & 1,472
\end{tabular}

H. Did Salesperson Fairly

Represent Exchange

Yes

No

Total

Sample size

$$
85.7
$$$$
\text { n.a. }
$$

$$
\frac{14 \cdot 3}{100 \cdot 0}
$$

8,920

\footnotetext{
*Source: Richard L. Ragatz for the Resort Timesharing Council of the American Land Development Association, 1979.
} 
Whether Have Requested Timeshare Trade, BY Selected Variables

Variable

Percent of Respondents By Whether Have Requested Trade Yes No Total

A. Length of Ownership

Less than 6 months

6 months up to 1 year

1 year

2 years

3 years

4 years or more

B. Average Purchase Price

C. Location of Timeshare Unit
12.3

23.6

24.5

45.7

56.8

60.9

$\$ 3,609$

18.9

27.2

30.4

33.7

30.9

51.2

32.8

30.4

41.3

22.2

19.3
87.7
76.4
65.5
54.3
43.2
39.1

$\$ 4,110$

81.1

72.8

69.6

66.3

69.1

48.8

67.2

69.6

58.7

77.8

80.7
100.0

100.0

100.0

100.0

100.0

100.0

Caribbean

H. Satisfaction with Time-

share Purchase

Very satisfied

Satisfied

So-so

Dissatisfied

Very dissatisfied

37.6

34.7

43.6

45.7

40.6
62.4

65.3

56.4

54.3

59.4
100.0

100.0

100.0

100.0

100.0

100.0

100.0

100.0

100.0

100.0

100.0

I. Type of Construction

New for timeshare

37.5

62.5

100.0

Conversion from condo

34.7

Conversion from hotel-major 33.7

65.3

100.0

66.3

100.0

Conversion from hotel-minor

47.0

53.0

100.0

*Source: Richard L. Ragatz for the Resort Timesharing Council of the American Land Development Association, 1979. 
* TABLE A- 18

Future Intended Use of Exchange Privilege, By Selected Variables

Percent of Respondents By Future Intended Use

Variable

\begin{tabular}{lr}
\hline $\begin{array}{c}\text { Every } \\
\text { Year }\end{array}$ & $\begin{array}{c}\text { Every } \\
\text { Other Ye }\end{array}$ \\
& \\
& \\
32.7 & 23.7 \\
27.2 & 22.7 \\
27.6 & 22.7 \\
27.9 & 24.4 \\
34.6 & 25.0
\end{tabular}
Every

Third Year Infrequently Never Don't

Total

A. Size of Unit

$\begin{array}{lll}\text { Studio } & 32.7 & 23.7 \\ 1 \text { bedroom } & 27.2 & 22.7 \\ 2 \text { bedrooms } & 27.6 & 22.7 \\ 3 \text { bedrooms } & 27.9 & 24.4 \\ 4 \text { bedrooms or more } & 34.6 & 25.0\end{array}$

5.7

5.7

5.1

5.0

1.9

$\$ 4,044$

$\$ 4,124$

$\$ 4,125$

$\$ 3,982$

C. Distance From Home

$\begin{array}{lll}\text { Less than } 25 \text { miles } & 43.3 & 20.2 \\ 25 \text { to } 49 & 32.5 & 24.0 \\ 50 \text { to } 99 & 32.2 & 23.9 \\ 100 \text { to } 149 & 31.9 & 23.7 \\ 150 \text { to } 249 & 25.9 & 23.5 \\ 250 \text { to } 499 & 32.1 & 17.4 \\ 500 \text { to } 999 & 29.4 & 21.7 \\ 1,000 \text { to } 1,999 & 20.0 & 22.8 \\ 2,000 \text { to } 2,999 & 21.7 & 24.3 \\ 3,000 \text { or more } & 17.6 & 25.9\end{array}$

2. 4

4.7

4. 3

4.5

5.1

5.3

5.4

7.0

7.1

8. 3
$25 \cdot 9$
7.6
7.7
8.6
7.7
10.9
10.9
12.9
17.1
13.1
12.5

2.9
2.5

23.6

2.5

28.7

1. 8

28.8

2. 5

30.5

32.1

3.0

31.3

2.5

28.1

3. 4

29.7

3.4

30.3

3.5

$\begin{array}{rr}8.2 & 1.8 \\ 11.3 & 2.2 \\ 11.4 & 2.8 \\ 11.4 & 3.0 \\ 7.7 & 1.9\end{array}$

27.9

3.10

30.3

28.4

28.8

100.0

100.0

100.0

100.0

100.0

100.0

100.0

100.0

100.0

100.0

100.0

100.0

100.0

100.0 


\section{*CONSUMER SATISFACTION}

During the past few years, much publicity has been directed at the issue of consumer satisfaction with any type of purchased product. This has been especially true with resort/recreational properties such as recreational lots, detached vacation homes and resort condominiums. In the early-1970's, a considerable amount of adverse publicity was directed at consumer fraud and dissatisfaction related to the recreational property market, especially raw land sales in remote areas of the country. In response, numerous consumer protection regulations were established along with environmental regulations. The entire market for real recreational property was blanketed with questioning concerns that helped lead to the demise of the market in the mid-1970's. While many quality products were being sold throughout this period, the stigma of consumer ripoff and dissatisfaction was unfortunately generalized to all recreational properties in all locations whether warranted or not. Much of this negative stigma remains today.

The objective of this section therefore is to attempt to ascertain how satisfied consumers of a relatively new type of recreational property (resort timesharing) appear to be and whether or not some of the same types of problems seem to be resurfacing in this market as were attached to the more traditional recreational properties.

Respondents in the survey were asked, "In general, how 
satisfied are you with your timeshare purchase?" As shown in Table VI-A, answers were overwhelmingly favorable with a very high 86.3 percent stating they were either "very satisfied" (44.6 percent) or satisfied ( 41.7 percent). only 4.5 percent responded in a negative manner. These findings are extremely close to those in the 1978 survey, but even more positive. For instance, in the recent survey, 44.6 percent of the respondents stated they were "very satisfied," while in 1978 , this response rate was 40.7 percent.

Respondents also were asked whether they would purchase their timeshare again if they knew at the time of purchase what they know now. This of course is a hypothetical situation, but again, if given a choice, only 12.4 percent would have changed their minds (compared to 14.0 percent in 1978) as shown in Table VI-B. The vast majority (72.5 percent) said they would do it over again and 15.0 percent said they did not know.

General Satisfaction According to specific Variables

In order to further explain what causes varying degrees of satisfaction amongst timeshare purchasers, the question concerning general satisfaction was cross-tabulated with several other questions. Results are briefly summarized below.

1. Length of ownership. The longer a respondent has owned their timeshare, the more they are 
satisfied with their purchase. For example, about 50 percent of those owning for two or more years were "very satisfied" whereas this proportion was only about 35 percent for those owning for less than six months.

2. Weeks purchased. As might be expected, respondents who bought two or more weeks are more satisfied with timesharing than those who bought just one week. About 40 percent of one-week purchasers were "very satisfied," whereas about 50 percent of the two-or-more-week purchasers checked this alternative.

3. Reasons for purchase. "Very satisfied" response rates were highest from buyers motivated by "liked timeshare unit" (53.7 percent), "opportunity to own recreational real property at low price" ( 52.3 percent), "certainty of having resort accommodations in the future" $(50.7$ percent), and "liked recreational amenities" (50.6 percent). They were considerably lower for "investment/resale potential" (39.9 percent), which again indicates resort timesharing (as other types of real property) should not be purchased or marketed under the perceived image of increasing one's wealth. The market is too young 
to have a proven resale market in terms of extensive equity appreciation, and the concept must be sold and consumed under the advantages associated with use rather than investment.

4. Distance from home. It is difficult to establish any pattern in regard to this variable. However, rates for "very satisfied" responses are lowest amongst respondents owning timeshares within 50 miles of their home (about 39 percent) and highest amongst those respondents owning timeshares about 1,000 miles distant (about 55 percent). The first situation perhaps is caused by the possibility that many respondents may have bought timeshares in their home community for investment rather than for personal use purposes. The second situation perhaps is caused by the possibility that many respondents may have bought higher quality timeshares in distant destination resort areas such as Hawaii, Florida, Mexico, etc.

5. Futureplans in market. An advantage of having satisfied buyers is noted in that 66.7 percent of respondents who intend to buy more timeshares at their present resort said they were "very satisfied" with their present unit. This rate was only 12.3 percent for those who said they intended to sell their present timeshare and buy 
no more. Some 19.5 percent of this latter group expressed some degree of dissatisfaction, whereas this proportion was only 0.2 percent for those in the former group. In other words, the more satisfied that buyers are with their present timeshare, the more they will buy in the future.

6. Age of household head. No significant differences appear to exist when comparing age of household head with degree of satisfaction, although older respondents tended to have higher probabilities of checking "very satisfied" than did younger respondents. For instance, about 47 percent of those over 55 checked "very satisfied" while only about 40 percent of those under 35 did so. This is probably because older respondents have purchased more expensive, higher quality timeshares.

7. Education of household head. "Very satisfied" responses increased considerably with education attainment. For example, 47.1 percent of the college graduates were in this category while the proportion was only about 40 percent for those with a high school degree or less. Again, this variation probably relates to income and the quality of timeshare unit purchased. 
8. Household income. Another definite-correlation exists between satisfaction and income, with the rate of response for "very satisfied" increasing with each income interval, being only 38.3 percent for those with 1979 annual incomes of less than $\$ 20,000$ and 57.7 percent for incomes of $\$ 100,000$ or more. As with age and education of household head, the variations probably are due to quality of timeshare unit purchased and resort location.

9. Type of use. Respondents who purchased fee timeshares checked the "very satisfied" response considerably more frequently than did those who purchased right-to-use timeshares, 47.6 percent compared to 31.5 percent. Summary of General Satisfaction Characteristics

From the preceding data, it appears the vast majority of timeshare purchasers are satisfied customers. Most would buy again in hindsight and most intend to buy additional timeshares. When cross-tabulating degree of satisfaction with several variables, it appears however that degree of satisfaction does vary according both to type of consumer and type of timeshare, as summarized on the following page. 
High satisfation is mos

apparent with respondents who:

1. have owned their timeshare longer

2. have purchased multiple weeks

3. have purchased higher priced timeshares

4. have purchased larger units with two or more bedrooms

5. have purchased for use or because they liked the unit

6. intend to buy more timeshares

7. have used their timeshare

8. have requested an exchange

9. have had an exchange confirmed

10. received their own first trade choice

11. were very satisfied with their trade

12. felt the exchange privilege was fairly represented by their salesperson

13. are middle age and above
Low satisfaction is most apparent with respondents who:

1. have just recently purchased their timeshare

2. have purchased only one week

3. have purchased lower priced timeshares

4. have purchased studios or one-bedroom units

5. have purchased for investment/resale purposes

6. intend to sell their present timeshare

7. have not yet used their timeshare

8. have not requested an exchange

9. have requested an exchanged but not had one confirmed

10. did not receive their own trade choice

11. were dissatisfied with their trade

12. felt the exchange privilege was unfairly represented by the salesperson

13. are young 
High satisfaction is most apparent with respondents who:

14. have attained higher education levels

15. have higher incomes

16. have purchased fee units

17. have purchased units in projects originally built for timeshare
Low satisfaction is most apparent with respondents wh

14. have not attained higher education levels

15. have lower incomes

16. have purchased rightto-use units

17. have purchased units which were converted hotels/motels with only minor renovations

Satisfaction with Specific Items

Another question concerning satisfaction with the timeshare purchase asked respondents to rate their degree of satisfaction with 13 specific items as shown in Table VI-C. Seven items relate to the timeshare unit itself while the others are concerned with on-site recreation or other amenities. Respondents were asked to rate their degree of satisfaction on a 1 (satisfied), 2 (so-so), or 3 (dissatisfied) scale.

The vast majority of timeshare buyers appear very pleased with their purchase. None of the seven items which related directly to the unit itself had a response rate of over three percent for "dissatisfaction." Only two (cleanliness of unit with 2.9 percent and storage space with 2.2 percent) had more than two percent of the buyers checking "dissatisfied." It is to be remembered that these responses came from almost 10,000 timeshare owners representing 183 different projects around the United states and 
elsewhere.

Rates of dissatisfaction were slightly higher for the other six items, but again almost negligible, Four of these items were checked by more than four percent of the respondents, including shopping ( 6.4 percent), restaurants ( 5.6 percent), recreation for children ( 4.6 percent), and responsiveness of management ( 4.3 percent).

It is interesting to note that several of the items most frequently checked in the "dissatisifed" column were ones which the timeshare resort developer probably has limited control over, e.g., restaurants, shopping, etc. However, several other items are more related to administrative/managerial aspects, e.g., "cleanliness of unit when you first checked in" and "responsiveness of management to your needs." It would be very unfortunate if the timeshare market became burdened with problems due to insensitive and relatively easy-to-remedy administrative issues.

*Source: Richard L. Ragatz for the Resort Timesharing Council of the American Land Development Association, 1979. 
A. General Satisfaction

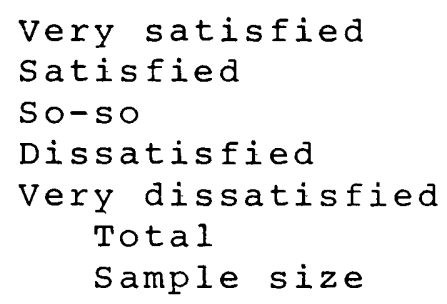

B. Would Purchase in Hindsight

$$
\begin{array}{r}
44.6 \\
41.7 \\
9.2 \\
2.6 \\
1.9 \\
\hline 100.0 \\
9,398
\end{array}
$$$$
\text { Sample size }
$$

$$
\begin{array}{r}
72.5 \\
12.4 \\
15.0 \\
\hline 100.0 \\
9,480
\end{array}
$$

C. Satisfaction with specific

\section{Items}

1. Size of unit

So-so

Dissatisfied

Not applicable Total

$$
\begin{array}{r}
91.0 \\
7.0 \\
1.2 \\
0.8 \\
\hline 100.0
\end{array}
$$$$
1,488
$$

40.7

44.1

10.8

2.4

$\frac{2.0}{100.0}$

1,488

$$
\begin{array}{r}
78.1 \\
14.0 \\
7.9 \\
\hline 100.0 \\
1,564
\end{array}
$$

2. Kitchen facilities

$$
\begin{aligned}
& \text { Satisfied } \\
& \text { So-so } \\
& \text { Dissatisfied } \\
& \text { Not applicable } \\
& \quad \text { Total }
\end{aligned}
$$

\begin{tabular}{rr}
90.4 & 88.0 \\
6.9 & 8.9 \\
1.3 & 2.0 \\
1.5 & 1.1 \\
\hline 100.0 & 100.0
\end{tabular}

3. Bathrooms
Satisfied
So-so
Dissatisfied
Not applicable Total


Table VI(Continued)

Percent of Respondents

1980 RTC Survey 1978 RCI Survey

4. Storage space

Satisfied

So-so

Dissatisfied

Not applicable

Total

5. Furnishings

Satisfied

So-so

Dissatisfied

Not applicable

Total

$$
\begin{array}{r}
78.3 \\
16.1 \\
2.2 \\
3.4 \\
\hline 100.0
\end{array}
$$

88.8

9.2

1. 1

$\frac{0.9}{100.0}$

$$
\begin{array}{r}
80.9 \\
16.5 \\
1.2 \\
1.3 \\
\hline 100.0
\end{array}
$$

Not applicable Total

$$
\begin{array}{r}
78.9 \\
10.7 \\
2.9 \\
7.5 \\
\hline 100.0
\end{array}
$$

Dissatisfied

Not applicable Total

8. On-site recreation

$$
\begin{aligned}
& \text { Satisfied } \\
& \text { So-so } \\
& \text { Dissatisfied } \\
& \text { Not applicable } \\
& \quad \text { Total }
\end{aligned}
$$

9. Nearby recreation

$$
\begin{aligned}
& \text { Satisfied } \\
& \text { so-so } \\
& \text { Dissatisfied } \\
& \text { Not applicable } \\
& \quad \text { Total }
\end{aligned}
$$

$$
\begin{array}{r}
73.8 \\
21.3 \\
3.0 \\
1.9 \\
\hline 100.0
\end{array}
$$

71.1

9.8

4.1

$\frac{15 \cdot 0}{100 \cdot 0}$

$$
\begin{array}{r}
15.7 \\
2.0 \\
2.3 \\
\hline 100.0
\end{array}
$$

79.7
15.2

2.0

$\frac{3.1}{100.0}$

88.0

1. 1

$\frac{2.0}{100.0}$

$$
\text { n.a. }
$$

\begin{tabular}{rr}
74.8 & 81.1 \\
18.9 & 14.9 \\
1.9 & 1.3 \\
4.5 & 2.7 \\
\hline 100.0 & 100.0
\end{tabular}


Table IV(Continued)

Percent of Respondents

1980 RTC Survey 1978 RCI Survey

10. Recreation for chilaren

Satisfied
So-so
Dissatisfied
Not applicable
$\quad$ Total

\begin{tabular}{rr}
47.7 & 54.5 \\
22.7 & 20.6 \\
4.6 & 4.1 \\
25.0 & 20.8 \\
\hline 100.0 & 100.0
\end{tabular}

11. Restaurants

Satisfied

64.9

68.3

So-so

Dissatisfied

Not applicable

Total

$\begin{array}{r}23.8 \\ 5.6 \\ 5.8 \\ \hline 100.0\end{array}$

22.7

4.9

$\frac{4.1}{100.0}$

12. Shopping

Satisfied

60.5

57.6

so-so

Dissatisfied

28.8

29.4

Not applicable

6.4

7.2

Total

$\frac{4.2}{100.0}$

$\frac{5.8}{100.0}$

13. Responsiveness of management

Satisfied

73.2

67.3

So-so

Dissatisfied

15.8

14.7

Not applicable

Total

4.3

4.1

$\frac{6.7}{100.0}$

$\frac{13.9}{100.0}$

D. Future Plans in Timeshare

Market

Do not plan to buy additional timeshares

40.2 *

46.4 *

Purchase additional time

36.9

25.4

at another resort

purchase additional time

at present resort

Attempt to sell present

timeshare but not buy

another one

9,390

1,564

(*Figures do not add to 100.0 percent because respondents could check more than one answer)

*Source: Richard L. Ragatz for the Resort Timesharing Council of the American Land Development Association, 1979. 
* TABLE A-9

Satisfaction With Timeshare Purchases, By selected Variables

Variable

Percent of Respondents By Degree of Satisfaction

$\begin{array}{llcl}\text { Very } & & \text { Very } \\ \text { Satisfied Satisfied } \quad \text { So-So Dissatisfied Dissatisfied } & \text { Total }\end{array}$

A. Length of Ownership

Less than 6 months
6 months to 1 year
year
2 years
3 years
4 years or more

B. Weeks Purchased

1
2
3
4
5

C. Average Purchase Price

D. Size of Unit

Studio
1 bedroom
2 bedrooms
3 bedrooms
4 or more bedrooms

E. Reasons for Purchase

Investment/resale

Exchange opportunity

Liked recreation

Liked unit

save money

certainty of accom.

Own property
$35 \cdot 9$
$40 \cdot 3$
$48 \cdot 2$
$48 \cdot 6$
$45 \cdot 5$
$52 \cdot 1$

51.8
44.2
38.8
38.0
39.2
36.9

$51 \cdot 8$

38.8

38.0

36.9

\begin{abstract}
39.2
46.1

56.4

60.5

55.1
\end{abstract}

$\$ 3,966$

36.2

40.1

47.1

47.7

37.7

39.9

42.5

50.6

53.7

42.6

50.7

52.3

\begin{abstract}
45.1
40.8

34.6

33.3

34.7
\end{abstract}

$\$ 3,900$

47.7

45.2

40.0

39.8

41.5

44.1

43.5

38.8

36.9

43.9

41.0

37.9

9.2
11.2
8.9
8.4
8.9
8.0

2.0

2. 5

2.4

2.6

3. 5

2. 4

3.0

2. 4

1. 8

1. 3

2. 1

5.6

$\$ 3,844$

$\$ 3,758$

2.5

3. 5

2.2

1. 9

9.4

7.5
$3 \cdot 1$
2.7
1.6
1.6
2.6
1.0
2.0
1.0

1.8

1.7

2.4

2.9

0.6

2.2

1. 7

0.3

0.4

2.4

$\$ 3,777$

2. 0

2.3

1.8

1. 6

3.8

2.3

1.6

1.0

0.9

1.6

1. 1

1.0
100.0

100.0

100.0

100.0

100.0

100.0

$$
\begin{aligned}
& 100.0 \\
& 100.0 \\
& 100.0 \\
& 100.0 \\
& 100.0
\end{aligned}
$$

100.0
100.0
100.0
100.0
100.0

100.0

100.0

100.0

100.0

100.0

100.0

100.0 
Table A-9 (Continued)

Percent of Respondents By Degree of Satisfaction

\begin{tabular}{cccc}
\hline Very & Satisfied & So-So Dissatisfied Dissatisfied Total
\end{tabular}

Variable

39.6

38.9

40.3

42.8

43.5

41.6

50.2

54.6

46.9

41.3

2,000 to 2,999

3,000 or more

G. Future Plans in Market

More time at present resort 66.7 More time elsewhere

No more time

sell what have

54.5

37.2

12.3

H. Have Used Timeshare

\section{Yes}

No

52.6
44.4

37.1

43.4

7.3

8.3

1.9

2. 2

1.1

1.7

100.0

$0.5 \quad 100.0$

1.4100 .0

$8.6 \quad 100.0$

I. Have Requested Trade

\section{Yes}

No
45.2

44.4
38.9

43.4
10.8
8.3
3.1

2. 2

2.0

1. 7

100.0 100.0 


\begin{tabular}{cccc}
\hline Very & Satisfied & So-So & Dissatisfied \\
Satisfiec & Dissatisfied 'otal
\end{tabular}

\section{J. Number of Trades Confirmed}

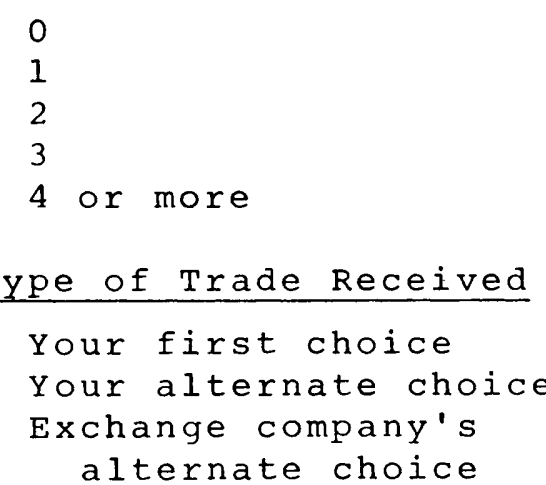

alternate choice

L. Satisfaction With Exchange

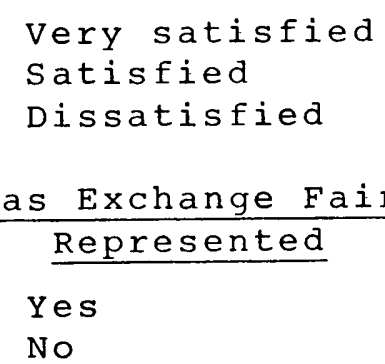

\section{Represented}

\section{Yes}

No

M. Was Exchange Fairly

N. Age of Household Head

\begin{tabular}{|c|c|c|}
\hline Un & er & \\
\hline 25 & to & \\
\hline 35 & to & \\
\hline 45 & to & \\
\hline 55 & to & \\
\hline 65 & or & \\
\hline
\end{tabular}

\section{5}

46.1

50.1

$51 \cdot 3$

$61 \cdot 7$

54.0

45.4

40.5

60.3

38.2

34. 1

50.1

16. 1

41.7

38.6

6.6

24.1

43.7

44.4

43.8

41.3

38.5

37.8

41.7

44.5

46.8

47.5

47.5

17.4
9.9
7.8
6.7
7.1

8.0

9.7

11.4

5.7

8.5

11.4

1.3
2.6
11.6

5. 9

2
.2
4. 5

1. 3

0.7

0.4

0

1. 4

0.5

2. 7

\begin{abstract}
9.5
12.7

7.7

8.2

8.5

9.0
\end{abstract}

0.9

11.8

3.1

2. 1

2.4

2.3

3.4

3.6 $\begin{array}{ll}0.6 & 100.0 \\ 1.2 & 100.0 \\ 4.3 & 100.0\end{array}$

0.6100 .0

9.4100 .0

$\begin{array}{ll}2.0 & 100.0 \\ 2.2 & 100.0 \\ 1.6 & 100.0 \\ 1.5 & 100.0 \\ 2.1 & 100.0 \\ 2.0 & 100.0\end{array}$


Table A-9 (Continued)

Percent of Respondents By Degree of Satisfaction

Very

Variable

Satisfied

Satisfied

So-So

Dissatisfied

Very

O. Education of Household Head

\begin{tabular}{|c|c|c|c|c|c|c|}
\hline Less than high school grad & 37.7 & 46.8 & 9.4 & 1.6 & 4.5 & 100.0 \\
\hline High school graduate & 42.1 & 43.3 & 9.6 & 2.7 & 2.3 & 100.0 \\
\hline Some college & 41.3 & 44.0 & 9.8 & 2.8 & 2.0 & 100.0 \\
\hline College graduate & 47.1 & 39.9 & 9.0 & 2.5 & 1.6 & 100.0 \\
\hline Graduate work & 47.3 & 40.5 & 8.4 & 2.4 & 1.4 & 100.0 \\
\hline
\end{tabular}

P. Household Income

Under $\$ 15,000$
$\$ 15,000$ to $\$ 19,999$
$\$ 20,000$ to $\$ 24,999$
$\$ 25,000$ to $\$ 29,999$
$\$ 30,000$ to $\$ 39,999$
$\$ 40,000$ to $\$ 49,999$
$\$ 50,000$ to $\$ 99,999$
$\$ 100,000$ or more

$$
\begin{aligned}
& 39.3 \\
& 38.3 \\
& 39.3 \\
& 40.6 \\
& 44.4 \\
& 49.2 \\
& 53.2 \\
& 57.7
\end{aligned}
$$

$\begin{array}{rr}43.8 & 11.0 \\ 44.6 & 11.6 \\ 45.0 & 10.6 \\ 45.3 & 9.6 \\ 43.1 & 8.7 \\ 39.4 & 8.0 \\ 35.2 & 7.3 \\ 33.1 & 7.5\end{array}$
3.3
3.4
2.6
2.9
2.2
1.8
2.8
0.8

$2.6 \quad 100.0$

2. 1

100.0

2.4

100.0

$1.7 \quad 100.0$

1. 5100.0

$1.8 \quad 100.0$

$8 \cdot 0$

100.0

0.8

100.0

Q. Type of Use Purchased

$\begin{array}{ll}\text { Fee } & 47.6 \\ \text { Right-To-Use } & 31 .\end{array}$

47.6
31.5

40.4

8.1

$48.3 \quad 13.3$

2.3

3.7

$1 \cdot 6$
3.2

100.0

Right-To-Use

R. Type of Construction

$\begin{array}{ll}\text { New for timeshare } & 46.5 \\ \text { Conversion from condo } & 44.7 \\ \text { Conversion from hotel-major } & 37.8 \\ \text { Conversion from hotel-minor } & 31.5\end{array}$

$46 \cdot 5$

37.8

Conversion from hotel-minor

$\begin{array}{lr}40.7 & 8.5 \\ 41.1 & 9.8 \\ 46.0 & 9.5 \\ 50.7 & 12.9\end{array}$

2.4

2.8

3.4

2.3

$\begin{array}{ll}1.9 & 100.0 \\ 1.5 & 100.0 \\ 3.4 & 100.0 \\ 2.6 & 100.0\end{array}$


1) Resort timesharing guarantees the use of a specific unit in a selected resort for a chosen amount of time, year after year

2) Timesharing offers, to some extent, a hedge against inflation since the buyer purchases future vacations at today's pricing.

3) Resort timesharing enables a person who can not afford a vacation home to purchase part ownership at a reduced price. Each purchaser pays only for the time that he will use the unit.

4) The timeshare purchaser may allow others to use his unit during his specified time period.

5) The timeshare purchaser may rent his unit.

6) The timeshare purchaser may sell his "share" at any time, to virtually anyone he wishes.

7) The timeshare purchaser may bequeath his "share" in his estate to anyone he wishes.

8) The timeshare purchaser can exchange his vacation weeks, depending on availability and membership rules, for vacations in any affiliated resort, for only a nominal fee. 
9) As an owner or member of the resort, the timeshare purchaser can enjoy most of the resort's facilities without charge.

10) The accommodations will probably provide a Iuxury that the timeshare purchaser had not thought he could afford.

11) In most cases the timeshare purchaser will be able to fix some or all of his meals in his unit; the convenience and savings will be significant.

12) In resorts that provide member or owner associations, the effect of inflation on management fees will be kept under control by the membership association. The timeshare purchaser has a voice or proxy vote via directors, in preventive or remedial action against inflationary impact.

13) The reduced cost for annual vacations should soon result in considerable savings over comparable rented accommodations.

14) The timeshare purchaser's vacations are virtually worry-free; management takes care of all maintenance chores before, during and after his visit.

15) Replacement of furnishings and equipment is provided for in the annual maintenance fee; 
there is no heavy burden on any one member, since expenses are spread out over all "sharers" of the unit.

\section{Limitations of Resort Timesharing}

1) The timeshare purchaser must take his vacation at the same time and same place each year, unless he can arrange an exchange.

2) The budget for annual maintenance could be grossly understated to promote sales and could quickly become too expensive.

3) The recreational facilities and other resort amenities that will be a part of the timeshare purchaser's financial maintenance responsibilities may not be of interest or fit the personal needs of the purchaser.

4) It is unlikely, but the developer could go broke.

5) The timeshare purchaser may have difficulty arranging to exchange his time unit with another resort if the time period does not occur during a peak season.

6) The timeshare purchaser can not furnish or redecorate the unit to his taste.

7) There is no guarantee that vacation costs are stabilized. ${ }^{2}$ 
${ }^{1}$ Keith w. Trowbridge, Resort Timesharing (New York, Simon and Schuster, 1981), p. 27.

2 Ibid., p. 29. 


\section{Future}

The timesharing industry has enjoyed rapid growth since its real emergence in 1975, and of major importance in the future growth of the industry is more leisure time for Americans in the coming years.

Initially the majority of those investing in timesharing were from above average income groups and were able to take the risk in a new venture. Now thousands of people with more modest incomes will be able to afford this type of vacation. 1

The future of timesharing will have its difficulties to overcome. The internal industry is subject to inflation, and acquisition cost for prime vacation properties are soaring. Construction costs are also rising along with the costs of labor, utilities and furnishings. These additional expenses will be reflected in future prices. ${ }^{2}$

Local legislation is not always favorable for timesharing. Interval resort timesharing provides a continual flow of tourists, community governments are concerned about the effects that this continual flow will have on community infrastructure and increased demand on utilities and natural resources. Strict zoning laws have resulted in elimination - of interval resorts in places like Lake Tahoe, Nevada, and some of the coastlines of Florida, Massachusetts, and California. ${ }^{3}$

Timesharing is continuing to grow and can now be found 
worldwide. It is an innovative idea, it continues to mature and change as it grows. It is possible that in the future the timesharing concept will extend to all types of vacations. They have already begun to timeshare campgrounds as well as luxury yachts, the possibilities are endless. ${ }^{4}$ As the resort timeshare industry expands with new resorts the sales of resort units will become appealing to the computerized real estate industry, and the mass marketing would further increase sales volume.

As the timesharing industry matures, the services needed for its smooth operation are beginning to emerge. New businesses and careers are being established to fulfill these needs. The exchange networks were first, and they are being followed by management services, public relations specialists, credit companies to finance sales and developers who are franchising their resort systems. 5

Consumers will benefit from the growth of timesharing. Franchise operations are making it easier for builders and resort operators alike to get their developments off the ground with less problems then if they had been on their own. As major developers begin to systematize their operations, standards within the industry should become even better.

Whatever direction resort timesharing ultimately takes, this newest development in vacationing will continue to offer vacationers all the benefits of an expensive second home 
without the burden of paying for the whole thing. It will also do something about inflation which might otherwise affect the quantity and quality of family vacations. 6 
${ }^{1}$ Keith w. Trowbridge, Resort Timesharing (New York, Simon and schuster, 1981), p. 174 .

${ }^{2}$ Ibid., p. 171 .

${ }^{3}$ Ibid., p. 171

${ }^{4}$ Ibid., p. 172

${ }^{5}$ Ibid., p. 173

${ }^{6}$ Ibid. , p. 173 . 
III. THE DATA AND THE TREATMENT OF THE DATA

The Data

The data for this study is of two kinds: primary data and secondary data. The nature of each of these types of ata will be given briefly below.

The primary data. The responses to the questionnaires of surveyed hotels/motels in the Fort Lauderdale Beach area.

The secondary data. The secondary data consists of published articles, pamphlets, books, and studies.

The Criteria Governing the Admissibility of the Data

Only responses which are full and complete will be admissible for this study.

only responses from hotel/motels that are on the beach or are directly across from the beach are admissible for this study.

Only responses from owners, managers, and sales representatives of hotels/motels surveyed will be admissible for this study.

The Research Methodology

Research methodology is dictated by the nature of the data. The researcher, by drawing conclusions from one transitory collection of data, may extrapolate what is

- likely to happen again under similar circumstances. The descriptive survey method of research, also called the normative survey method, looks with intense accuracy at what is happening at a particular moment and then describes 
exactly what the researcher sees. The basic assumption underlying this approach is that whatever is observed at any one time is normal and under the same conditions, could conceivably be observed at any time in the future. It assumes that given phenomena usually follow a common pattern, or norm.

In his book, Practical Research, Planning and Design, Paul D. Leedy points out the important characteristics of the descriptive survey as given below.

1. The descriptive survey method deals with a situation that demands the technique of observation as the principal means of collecting data.

2. The population for the study must be carefully chosen, clearly defined, and specifically delimited in order to set precise parameters for insuring discreteness to the population.

3. Data in descriptive survey research are particularly susceptible to distortion through the introduction of bias into the research design.

4. Although the descriptive survey method relies upon observation for acquisition of the data, those data must be organized and presented systematically so that valid and accurate conclusions may be drawn from them. 
The Specific Treatment of Each Problem

The first subproblem. The first subproblem is to determine whether timesharing is a natural extension of the resort industry, or of the real estate industry, and in which sector it exerts the most influence.

Data needed. The data needed to solve the first subproblem is: the replies of the respondents to the specific area of the questionnaire that relate to timesharing.

The location of the data. The data is found in the replies to the questionnaire of hotel/motel owners, managers and/or sales managers of the selected fort Lauderdale area beach hotel/motels.

The means of obtaining the data. The replies of the respondents will be obtained by means of a questionnaire. Appendix A contains a copy of the questionnaire that was distributed. The data has been safeguarded to insure the anonymity of the hotel/motels throughout the study.

The treatment and interpretation of the data.

How the data will be screened. The questionnaires will be screened to eliminate those in which all the questions have not been answered.

How the item analysis will be made. The goal of analyzing this subproblem is to determine whether timesharing is a natural extension of the resort industry, or of the real estate industry, and in which sector it exerts the most influence. Therefore the 
data from questions 10, 11 , and 15 will be expressed in percentage form, and will be correlated with the personal data information section of the questionnaire. How the data will be interpreted. The data will be interpreted by counting the number of positive and negative replies in order to arrive at a percentage of the total responses, and by correlating these percentages with personal data. These methods of interpretation will be utilized to determine whether timesharing is having a strong effect on the resort industry or whether it may have a greater effect on the real estate industry.

The second subproblem. The second subproblem is to determine whether timesharing is specifically suited only for these times, or will it become a firmly established concept in the future.

Data needed. The data needed to solve the second subproblem is: the replies of the respondents to the specific area of the questionnaire that relates to whether or not timesharing is specifically suited only for these times, or will it become a firmly established concept in the future.

The location of the data. The data is found in the replies to the questionnaire of hotel/motel owners, managers, and/or sales managers of the selected Fort Lauderdale area beach hotel/motels. 
The means of obtaining the data. The replies of the respondents will be obtained by means of a questionnaire. Appendix A contains a copy of the questionnaire that was distributed. The data has been safeguarded to insure the anonymity of the hotel/motels throughout the study.

The treatment and interpretation of the data.

How the data will be screened. The questionnaires will be screened to eliminate those in which all the questions have not been answered.

How the item analysis will be made. The goal of analyzing this subproblem is to determine whether timesharing is specifically suited only for these times, or will it become a firmly established concept in the future. Therefore the data from questions 8 , 9, 12, 13, 14 will be expressed in percentage form, and will be correlated with the personal data information section of the questionnaire.

How the data will be interpreted. The data will be interpreted by counting the number of positive and negative replies in order to arrive at a percentage of the total responses, and by correlating these percentages with personal data. These methods of interpretation will be utilized to determine whether timesharing is specifically suited only for these times, or will it become a firmly established concept in the future. 
IV. GENERAL PROCEDURE

Determining the Design of the sample

Sample size depends largely on the degree to which the sample population approximates the qualities and the characteristics found in the general population. There are six steps that must be taken in designing a sample:

1. What is the relevant population?

2. What type of sample shall we draw?

3. What sampling frame shall we use?

4. What are the parameters of interest?

5. What size sample is needed?

6. How much will the sample cost? ${ }^{1}$

A questionnaire survey was conducted to obtain data for the study. The population used in this study was the hotels located in the Fort Lauderdale Beach area. The characteristics of this population are homogeneous in nature. They are all lodging facilities located in the same geographical area and their facilities and services are available to the public traveler.

The sample is only a partial reflection of the population from which it is drawn. The sampling frame of this population was prepared from the yellow pages of southern - Bell's Fort Lauderdale telephone book, 1981-1982. The frame made up a total of 150 hotels, located on the beach or directly across from the beach.

The sample size is based on attributes data by making 
subjective decisions concerning the acceptable interval estimate and the degree of confidence. ${ }^{2}$ The acceptable confidence level of $95 \%$ will be established. This means that the researchers have a $95 \%$ assurance that only $5 \%$ of the time the results of the sample would not be within the $10 \%$ margin of error.

A margin of error of $\pm 10 \%$ is acceptable because the concept of timesharing is relatively new, and not many studies of this kind have been undertaken. Also, the Fort Lauderdale Beach hotel/motels were at the peak of their tourist season at the time of this study, and therefore many owners, managers, and/or sales managers did not have the time to answer the questionnaire. Many of those who did complete the questionnaire, were under time constraints and were only able to give the questionnaire superficial attention.

Identifying the sample is important but difficult. The difficulty arises when determining the sample procedure. The sample must be representative of the population or the end result of the survey will be distorted. A systematic sampling method was used for selecting the sample of hotel/motels. Systematic sampling is the selection of - certain hotels according to a predetermined sequence. In this study every third hotel/motel of the frame was selected as a sample hotel/motel. The researchers believe that this method of selecting a segment of the population will provide reliable information. 
Collection of the Data

A personal questionnaire (Appendix A) was used to collect the data from the drawn sample. The researchers personally delivered the questionnaires, and waited while they were completed, the researchers found this to be the most appropriate and applicable type of research method. The researchers believe this to be the best technique because it is the most effective and efficient in yielding the highest response rate. The personal interaction gave the researchers the opportunity to obtain additional information, rather than to be limited only by the survey questions. The drawback of the personal questionnaire, is that the researchers may bias the respondents replies, and therefore it is important to recognize that there is a constant potential for response errar.

The response structure of the questionnaire may be classified as both open and closed. In the open form respondents are free to reply with their own choice of words and concepts. In the closed form the respondent chooses from two or more predetermined response possibilities, in this questionnaire the response possibility was limited to a yes or no response. The questionnaire was designed to be complete, relevant, brief and easy to fill out. The questionnaire obtained personal data on the hotel/motels, as well as data concerning respondents attitudes towards timesharing. 
To ensure the questions were stated properly, the questionnaire was pretested by the researcher at six hotels in the sample. Two managers, two owners, and two sales managers were the respondents of the pretest analysis of the questionnaire. After the pretest, the questionnaire was finalized by the researchers by making some revisions and by adding an additional question.

Sampling of Attributes

Once the questionnaire has been designed, it is necessary to determine the number of completed surveys needed to determine a significant statistical sample size. The measure of concern with attributes data is $P$ (the proportion of the population that has given attribute). The variance is measured in terms of $\mathrm{PxQ}$ ( $Q$ representing the proportion not having the attribute).

The formula to employ is:

$$
Q P=\frac{P Q}{n-1}
$$

In order to employ this formula preliminary questioning, using the results from question 8 provided the researchers with the variance estimated.

The calculation would be as follows:

Data:

$$
\begin{aligned}
& 0.10=\text { desired internal range, within the population } \\
& \text { proportion is expected. } \\
& 1.960 . \mathrm{P}=0.95 \text { confidence level for estimating } \\
& \text { interval within which to expect the }
\end{aligned}
$$




$$
\begin{aligned}
& \text { population proportion, } 1.96 \text { is the } \\
& \text { factor considering the tables and is } \\
& \text { therefore considered a datum. } \\
& \text { O.P. }=0.051=\text { the standard error of the } \\
& \text { proportion }(0.10 / 1.96) \\
& \text { P.Q. = } \text { measure of simple dispersion. }
\end{aligned}
$$

Formula

$$
Q \cdot P \cdot=\frac{P \cdot Q}{n-1}=.051=\frac{.9 x \cdot 1}{n-1}
$$

Therefore 36 samples will be needed in order to make the outcome of the research representative. 


\section{FINDINGS AND CONCLUSIONS}

Questionnaire Response

The researchers hand-delivered the questionnaire (Appendix A) to fifty-four hotels/motels in the Fort Lauderdale Beach area in the attempt to obtain the necessary sample size of thirty-six responses. In order to receive open and honest answers, the questionnaires exclude the name of the hotels/motels surveyed. The questionnaires were coded by a number. These numbers were recorded separately along with the corresponding names of the hotels/motels. In addition to keeping the questionnaires anonymous, the questionnaires indicated that the area surveyed included hotels/motels from Miami to west Palm Beach. The purpose for doing this was to make the respondents feel as though their hotels/motels were undistinguishable because of the enlarged sample size.

The researchers came across certain problems in obtaining responses to the questionnaires. The major problem encountered was the bias of many of the motels against timesharing. This bias is the result of negative contact with representatives of the timesharing industry. Most of these motels have been approached by people interested in converting the properties to timesharing. Many of these people have used deceptive methods to secure information for their own purposes. This has resulted in resentment as well as defensiveness on the part of the motel operators. 
Another problem was that during the two week period while the survey was being conducted, the hotels/motels in the Fort Lauderdale Beach area were at the height of their season. Therefore, many refused to answer the survey while others answered the questions as quickly as possible. In all research studies a margin of error is created. In this particular study, a sample of the hotels/motels in the Fort Lauderdale Beach area were surveyed rather than the entire population. The use of a sample population instead of the entire population always results in a margin of error.

Findings

The First Hypothesis

The first hypothesis is that timesharing is a natural extension of the resort industry. The data from questions 10, 11 and 15 was used to analyze this hypothesis. The analysis of the data expressed in percentage form supports the hypothesis.

The data from question 15 most clearly supports the belief that timesharing is a natural extension of the resort industry. Of all those surveyed, $58 \%$ of the respondents agreed with this hypothesis. However the analysis of

- questions 10 and 11 indicates that most operators do not find timesharing to be causing competition at this time or in the future. Question 10 indicates that 918 of the respondents feel that, at the present time, timesharing 
is causing no direct competition. The results of question

11 reveals that $83 \%$ of those surveyed do not believe that timesharing will cause competition in the future. In general the majority of the hotels/motels surveyed do not feel that timesharing causes them competition now and will not cause competition in the future. This is because at this point timesharing is still a young industry and has often had the effect of improving hotel/motel occupancy by absorbing excess rooms. Many of the hotels/motels surveyed have indicated that their occupancies have improved since timesharing has moved into the neighborhood. They believe that the continued growth of timesharing will have a positive effect on occupancy since less units will be available as an increasing number of hotels/motels convert to timesharing. The responses of the operators and their beliefs in the positive effects of timesharing suggests that they feel that timesharing has a significant impact on the resort industry.

While conducting the survey in the Fort Lauderdale Beach area, the researchers discovered a number of timeshare properties interspersed among the motels. All of these properties have been converted from motels to the timesharing concept within the last five years. The interior designs of the timeshare properties have been modified, however basically they are not much different from the surrounding motels except that their units are purchased in weekly intervals. Both the timeshare properties and the motels 
pursue the same market segments and also attract the same market segments. These findings further support the data from the questionnaires and thus our first hypothesis that timesharing is a natural extension of the resort industry.

\section{The second Hypothesis}

The second hypothesis is that timesharing is suited for these times and is capable of becoming a firmly established concept in the future. The data from questions 8, 9, 13 and 14 was used to analyze this hypothesis. The analysis of the data expressed in percentage form partially supports the hypothesis.

Questions 8 and 9 indicate that a large percent of the hotel/motel operators have noticed the growth of timesharing in the Fort Lauderdale Beach area and think that it will continue to grow in the future. Of all these surveyed 83\% have noticed the growth of vacation timesharing in the area and $58 \%$ think it will continue to grow in the future. These results indicate that hotel/motel operators believe that vacation timesharing has developed because it is specifically suited for these times. However the data is not conclusive with respect to whether or not it will become - a firmly established concept in the future.

$$
\text { Questions } 13 \text { and } 14 \text { indicate that operators of }
$$
hotels/motels in the Fort Lauderdale Beach area do not see vacation timesharing as being a solution to seasonal 
fluctuations in occupancy while $61 \%$ said no and $28 \%$ answered maybe to this question. The analysis of question 14 indicates that $25 \%$ of the respondents see vacation timesharing as profitable alternatives for their properties while $66 \%$ do not and $8 \%$ are uncertain.

Most of the hotel/motel operators do not feel that vacation timesharing would be a solution to season fluctuations because they do not believe that they could sell out their properties at $100 \%$, year-round. Many of the operators mentioned to the researchers that it would be just as difficult to achieve $100 \%$ occupancy in the summer for timesharing properties as it would be for hotel/motel properties located in the Fort Lauderdale Beach area. A large percent of hotel/motel operators indicated that they do not see timesharing as a profitable alternative for their properties. In many cases this is due to a negative predisposition towards timesharing. Hotel/motel operators have been deceived by timeshare representatives and have also received many complaints from their guests who have been harassed by timeshare people. Many of the motel operators revealed that while timesharing might be profitable, they do not - consider it an alternative for their properties. This is because many of the owners are happy with their motels and do not want to make any changes. 
The results of questions 8 and 9 of the survey support the hypothesis while the data from questions 13 and 14 only partially support the hypothesis. This contradiction of the data can be attributed to the negative bias towards timesharing apparent in many of the operators. The researchers feel that this bias has affected the operators' objectivity and that there is really stronger support for the hypothesis than is indicated by the survey results. 
Questions
Percent of Respondents

Owners Managers Sales Managers

\#7 Do you know what vacation timesharing is?

Have you noticed the growth of vacation timesharing in the Fort Lauderdale Beach area?

Yes

Yes

No

Maybe

$100 \%$

$-$

1008

No

$66 \%$

Maybe

$22 \%$

$11 \%$

$90 \%$

$5 \%$

$5 \%$

$80 \%$

$20 \%$

$-$

\#9 Do you think vacation timesharing will continue to grow in the Fort Lauderdale Beach area?

Ye

No

$56 \%$

548

$27 \%$

Maybe

$4 \overline{4}$

$18 \%$

$80 \%$

$44 \%$

$20 \%$

\#10 Has vacation timesharing caused any direct competition with your property?

Yes

No

$88 \%$

Maybe

$11 \%$

$5 \%$
$90 \%$

$100 \%$

$-$

Yes $\quad 11 \%$

No $66 \%$

$20 \%$ $80 \%$ 
Percent of Respondents

Questions

$\begin{array}{lcc}\text { Owners } & \text { Managers } & \text { Sales Managers } \\ \text { Total-8 } & \text { Total-23 } & \text { Total-5 }\end{array}$

\#12 Do you forsee an increasing number

of resort properties, located on

the beach in Fort Lauderdale,

converting to the timesharing

concept?

$\begin{array}{ll}\text { Yes } & 44 \% \\ \text { No } & 33 \% \\ \text { Maybe } & 22 \%\end{array}$

$45 \%$

458

$40 \%$

Maybe

$22 \%$

98

$60 \%$

\#13 Can you see vacation timesharing

as being a solution to seasonal

fluctuations in the occupancy

of your property?

\#14 Could you see vacation timesharing as a profitable alternative for your. property?

\#15 Do you perceive timesharing as having a greater effect on the resort industry than on the real estate industry?

\section{Yes}

No

Maybe

$\begin{array}{ll}\text { Yes } & 44 \% \\ \text { No } & 33 \% \\ \text { Maybe } & 22 \%\end{array}$

$11 \%$

$44 \%$

$11 \%$

98

$64 \%$

$27 \%$

$20 \%$

$80 \%$

$-$

Maybe

$22 \%$

$22 \%$

728

48

$100 \%$

-

$\begin{array}{lrrr}\text { Yes } & 55 \% & 63 \% & 40 \% \\ \text { No } & 33 \% & 32 \% & 20 \% \\ \text { Maybe } & 11 \% & 4 \% & 40 \%\end{array}$


TABLE II

Personal Data Expressed in Percentage Form

\#3 Who is your target market?

Market segment

Business Persons

$21 \%$

Families

$39 \%$

students

$22 \%$

Conventions

$5 \%$

Other

$12 \%$ 
\#10 Has vacation timesharing caused any direct competition with your property?

\begin{tabular}{|c|c|c|c|c|c|c|}
\hline Yes & - & - & - & - & - & 78 \\
\hline No & $100 \%$ & $75 \%$ & $86 \%$ & $100 \%$ & $100 \%$ & 938 \\
\hline Maybe & - & 258 & $14 \%$ & - & - & - \\
\hline Yes & - & - & $14 \%$ & - & - & $7 \%$ \\
\hline No & $75 \%$ & 758 & $86 \%$ & $100 \%$ & $100 \%$ & $86 \%$ \\
\hline Maybe & $25 \%$ & $25 \%$ & - & - & - & $7 \%$ \\
\hline Yes & $25 \%$ & 258 & 718 & $50 \%$ & $100 \%$ & $50 \%$ \\
\hline No & $50 \%$ & 508 & 298 & $33 \%$ & - & 438 \\
\hline Maybe & $25 \%$ & $25 \%$ & - & 178 & - & 78 \\
\hline Yes & - & - & 298 & $33 \%$ & - & $7 \%$ \\
\hline No & $50 \%$ & $50 \%$ & $57 \%$ & $50 \%$ & $100 \%$ & $71 \%$ \\
\hline Maybe & $50 \%$ & $50 \%$ & $14 \%$ & $17 \%$ & - & 218 \\
\hline $\begin{array}{l}\text { Yes } \\
\text { No }\end{array}$ & $\begin{array}{l}25 \% \\
50 \%\end{array}$ & $\begin{array}{l}25 \% \\
50 \%\end{array}$ & $\begin{array}{l}43 \% \\
86 \%\end{array}$ & $\begin{array}{l}33 \% \\
67 \%\end{array}$ & $\overline{100 \%}$ & $\begin{array}{l}14 \% \\
79 \%\end{array}$ \\
\hline
\end{tabular}

\#11 Do you forsee vacation timesharing causing competition for your property in the future?

\#12 Do you forsee an increasing number of resort properties, located on the beach in Fort Lauderdale, converting to the vacation timesharing concept?

\#13 Can you see vacation timesharing as being a solution to seasonal fluctuations in the occupancy of your property? 
TABLE IV

Personal Data Correlations

\#6 - What is your approximate occupancy \& per season?
\#13 - Can you see vacation timesharing as being a solution to the seasonal fluctuations in the occupancy of your property?
Yes
No
Maybe

\section{Winter}

$$
\begin{aligned}
& 0-24 \\
& 25-49 \\
& 50-74 \\
& 75-100
\end{aligned}
$$

Spring

$$
\begin{aligned}
& 0-24 \\
& 25-49 \\
& 50-74 \\
& 75-100
\end{aligned}
$$

Summer

$$
\begin{aligned}
& 0-24 \\
& 25-49 \\
& 50-74 \\
& 75-100
\end{aligned}
$$

Fall

$$
\begin{aligned}
& 0-24 \\
& 25-49 \\
& 50-74 \\
& 75-100
\end{aligned}
$$

-

$15 \%$

$100 \%$

-

$16 \%$

$33 \%$

$16 \%$

-

$100 \%$
$12.5 \%$
$15 \%$

-

-
-
688

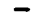

$100 \%$

$18 \%$

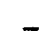

$40 \%$

$16 \%$

$68 \%$

338

$33 \%$

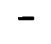

$-$

$38 \%$

258 
TABLE V

Personal Data Correlations

\#4 - What is the average length of stay of your guests?

\# 3 Can you see vacation timesharing as being a solution to seasonal fluctuations in the occupancy of your property?

Yes

No

Maybe

\#14 Could you see vacation timesharing as a profitable alternative for your property?

$\begin{array}{ll}\text { Yes } & 20 \\ \text { No } & 60 \\ \text { Maybe } & 20\end{array}$

\#15 Do you perceive timesharing as having a greater effect on the resort industry than on the real estate industry?
$20 \%$

$50 \%$

$30 \%$

$20 \%$
$60 \%$

208
$27 \%$
$72 \%$
$-$

$90 \%$

$64 \%$

$27 \%$

$10 \%$

$80 \%$

$10 \%$

$20 \%$

$40 \%$

$40 \%$

$\begin{array}{ll}\text { Yes } & 50 \\ \text { No } & 30 \\ \text { Maybe } & 20\end{array}$

$54 \%$

$36 \%$

$9 \%$
$20 \%$

$70 \%$

$10 \%$

$40 \%$

$60 \%$

$-$

$70 \%$

$30 \%$

$60 \%$

$30 \%$

$20 \%$ 
\#8 Have you noticed the growth of vacation time-

\#9 Do you think vacation timesharing will continue

to grow in the Fort Lauderdale Beach area?

\#10 Has vacation timesharing caused any direct competition with your property?

\#11 Do you forsee vacation timesharing causing competition for your property in the future?

\# 2 Do you forsee an increasing number of resort properties located on the beach in Fort Lauderdale, converting to vacation timesharing?

\#13 Can you see vacation timesharing as being a solution to seasonal fluctuations in the occupancy of your property?

\#14 Could you see vacation timesharing as a profitable alternative for your property?

\#15 Do you perceive timesharing as having a on the real estate industry? 
In view of these findings, the researchers conclude that timesharing is a natural extension of the resort industry, and that timesharing is suited for these times, and is capable of becoming a firmly established concept in the future.

There are opportunities for the unlimited growth of timesharing in the Fort Lauderdale Beach area, most of the existing timeshare properties in this area have been converted from motels. Although our surveys indicate that many of the operators approached would not consider converting their properties to timesharing, the researchers believe that, in fact, the probability of conversion is greater. Many motel operators may be forced to sell to timeshare developers due to economic reasons. Over time as the motels deteriorate the operators will be faced with rising replacement costs which may necessitate them to sell their properties. If these operators are unable to afford the renovations, they will be faced with the decision of whether to search for outside means of financing or whether to sell.

In order for timesharing to be successful, it must be located near some attraction. Therefore the Fort Lauderdale Beach area is attractive and timeshare developers are anxious to acquire Beach properties. This has been verified by many of the operators surveyed who indicated that timeshare representatives have approached them and shown interest in their properties. Therefore it can be assumed that if any 
of these motel properties were to be put on the market, timeshare developers would be natural prospective buyers. The researchers feel that the timesharing concept is adaptable to change and will continue to grow in the future. However its growth potential is limited by the bias of many operators against timesharing. This bias has also affected the present growth of timesharing. Fear of the unknown is a major factor contributing to this bias. Timesharing is a relatively new concept which many operators do not fully understand. This lack of complete knowledge is the major cause of fear and uncertainty. Like most people, the motel operators are afraid of change and are therefore uncomfortable with the timesharing concept which is new and different and has created change in the neighborhood. Their opinions have also been influenced by the harassment and deception they have encountered from timesharing representatives. This bias and subsequent uncertainty is mainly due to their fear of the ramifications of timesharing. Some unanswered questions include: Will timesharing have positive or negative effects on their occupancies? Will timesharing necessitate changes in the operations of their properties? Will they be able to survive the competition?

There are other motel operators who are not biased against timesharing. They do not feel threatened by the timesharing concept. Many of these operators have felt benefits from the entrance of timesharing in the resort industry. 
A few respondents have felt positive effects from timesharing. These effects are increased occupancy rates due to a decrease in the number of room nights available to be rented on a daily basis. Most of the respondents indicated their beliefs that timesharing would become even more beneficial to them in the future. As timesharing continues to grow, mainly by means of renovating motels, the number of motel rooms available on the Beach will be lessened. This will cause an increase in business for the remaining motels.

The results of the questionnaires support our hypothesis that timesharing is a natural extension of the resort industry and that is is suited for these times. The results also indicate that the assumption that timesharing is capable of becoming a firmly established concept is questionable. After an in-depth study of the subject of timesharing, the researchers feel qualified to take an objective position on the subject. The researchers believe timesharing to be an extension of the resort industry. Timesharing has been developed specifically for these times and can be adapted so as to become a firmly established concept in the future. Any contradictions found in the data or disparity between the ideas of the researchers and respondents could be attributed to the respondents' lack of knowledge and negative bias towards timesharing.

It is important to note that it is not possible to construct a new timeshare resort because of the lack of available property in the Fort Lauderdale Beach area. 
Therefore all references to timesharing in the responses to the questionnaires and in the analysis of those responses refer to converted motel properties. These results do not necessarily apply to properties specifically constructed for timesharing.

The researchers feel that timesharing will continue in the future. Therefore it is important to familiarize the public with the concept. Some of the most important factors to consider when purchasing a timeshare unit are: to make sure that the developer is legitimate; the unit should not be purchased as an investment because at this time there is no resale market; the unit should be purchased for vacation pleasure; it is best to purchase a time period which is most suited to your needs; it is important to be certain that the developer has a valid, existing contract with an exchange service; if the purchaser is planning to trade his unit, it is best to buy an interval at the height of the season; it is necessary to realize that there is a yearly management fee that can increase with inflation. Although timesharing still has some difficulties to overcome, the researchers believe that if proper investigation is carried out, resort timesharing can be a rewarding vacation alternative. 
VITA

Lisa Aufzien was born on April 10, 1958 in Passaic New Jersey. She graduated in May 1980 from Vassar College, Poughkeepsie New York, with a Bachelors of Arts in Psychology. In september of 1980 she entered Florida International University's School of Hospitality Management where she is seeking her Master of science degree.

Julie krimmer was born in New York on March 5, 1957. Her high school education was completed at East Meadow High School, East Meadow, New York. In 1979, she received a Bachelor of Arts degree in Rhetoric and Communications from the State University of Albany, Albany, New York.

For the next year and a half she worked in New York City before continuing her education. In 1982 she successfully completed a Master's of Science Degree in Hospitality Management at Florida International University. 


\section{APPENDIX A}

\section{Timesharing Questionnaire}

Lisa Aufzien

Julie Krimmer

We are taking a survey of Hotel/Motel beach properties from Miami to west Palm Beach. The results of the survey will be utilized in our Masters Thesis for the Hospitality School at Florida International University. We appreciate your cooperation. The results of this survey will be kept completely confidential.

1. What is your position in the Hotel/Motel?

2. How many units in your Hotel/Motel?

3. Who is your target market? (Please check the appropriate responses)

Businesspersons

Families

Students

Conventions

other

4. What is the average length of stay of your guests?

5. Do you have a large percentage of repeat guests? 
6. What is your approximate occupancy in each of the following seasons?

Winter

Spring

Summer

Fall

7. Do you know what Vacation Timesharing is?

8. Have you noticed the growth of vacation timesharing in the Fort Lauderdale Beach area?

9. Do you think vacation timesharing will continue to grow in the Fort Lauderdale Beach area?

10. Has vacation timesharing caused any direct competition with your property? (Has it affected your room sales?)

11. Do you forsee vacation timesharing causing competition for your property in the future?

12. Do you forsee an increasing number of resort properties, located on the beach in Fort Lauderdale, converting to the vacation timesharing concept?

13. Can you see vacation timesharing as being a solution to seasonal fluctuations in the occupancy of your property? 
14. Could you see vacation timesharing as a profitable alternative for your property?

15. Do you perceive timesharing as having a greater effect on the resort industry, than on the real estate industry? 


\section{BIBLIOGRAPHY}

Bettner, Jill, Editor, "Personal Business," Business Week, June 4, 1979, p. 121-122.

Boster, Alyce, "Marketing the Timeshare Unit," Real Estate Review, Spring 1975, p. 104-108.

Brener, Steve, "Timesharing Makes its Mark," Lodging Hospitality, June 1978, p. 38 .

Burlingame, Carl, The Buyer's Guide to Resort Timesharing, Los Altos, California, The CHB Company, Inc., 1981

Chadwick, Bruce, "Buy Time," House Beautiful, October 1979 , p. 91-102.

Crosson, stephen T., MAI, SRPA, and Dannis, Charles G., SRPA, "Timesharing Ownership in Resort Developments," The Appraisal Journal, April 1977, p. 167-172.

Curtis, Carol E., "Endless Vacation or Endless Headache?", Forbes, september 14, 1981, p. 114-118.

David, George I., and Goldman, Leslie, "Managing a Timeshare Resort," Journal of Property Management, September/ october 1980, p. 266-269.

Davis, Thomas J., "Timesharing Ownership: Possibilities and Pitfalls," Real Estate Review, Winter 1976, p. 49-54.

Davis, Thomas J., "Timesharing Exchange Networks," Real Estate Review, Fall 1978, p. 42-45.

Dunn, Dennis G., "Lending to the Resort Timesharing Industry," The Journal of Commercial Bank Lending, August 1981 , p. 24-34.

Ellsworth, David G., and Pendergast, James D., "Securities Maze Awaits Resort Timeshare Offerings," Real Estate Review, Spring 1980, p. 59-64.

Emory, C. William., Business Research Methods, Homewood, IL., - Richard D. Irwin, Inc., 1976, pp. 138-154.

Gerardi, Natalie, "Update on Timesharing," House and Home, March 1976, p. 84-87.

Gerardi, Natalie, "Timesharing," House and Home, November $1974, \mathrm{p} .72-77$. 
Guenther, Robert, "Timeshares Can Be Safe Buy, But Be Wary of Prices, Hype," The Wall Street Journal, March 24, 1982, p. 29 .

Guest, Elizabeth, "How to Vacation Like the Rich People Do," Next, June 1981, p. 1-3.

Harney, Kenneth P.," How Good is Timesharing?," 50 Plus, May 1981, p. 56-57.

Hart, Christopher W., "Timesharing: Part of the Hotel Equation," The Cornell H.R.A. Quarterly, November 1980, p. 49-57.

Hice, Joe, "Florida's New Hot Market: The Timeshare Condominium," Florida Trend, september $1980, \mathrm{p} .1-2$.

Ilvento, Charles L. C.P.A., "Vacation Timesharing Plans," The Cornell H.R.A. Quarterly, May 1976, p. 15-21.

Leedy, Paul D., Practical Research, Macmillan Publishing Co., Inc., 1980 .

Luciano, Lani, "The Trouble with Timeshares," Money, October $1981, \mathrm{p}$. 110-114.

Malleris, Leonidas C., "Five Legal Hurdles in Timeshare Ownership," Real Estate Review, Summer 1978, p. 97-101.

Myers, Peter, "Timesharing a Condominium", Executive, June 1981, p. 46-48.

Ragatz, Richard L., The Ragatz Study, Washington D.C., The Resort Timesharing Council of the American Land Development Association, 1979 .

Rosen, Robert J., "Structure That Timeshare Conversion as a Cooperative:," Real Estate Review, Fall 1980, p. 35-41.

Sacks, Alan, "A Holiday Home Through A Timesharing Scheme?," Accountancy, September 1980, p. 70-74.

Shane, Sheldon, "Timesharing Vacations," Travel/Holiday, June 1981, p. 32 .

Sugg, John, "Timesharing: It's a Profitable Boom for Florida's Promoters," Miami Business Journal, February $16,1981, \mathrm{p} .17-20$. 
The Resort Timesharing Council of the American Land Development Association, Resort Timesharing: A Consumers' Guide, Washington, D.C., 1980 .

The Resort Timesharing Council of the American Land Development Association, Resort Timesharing Fact sheet, Washington, D.C., 1982 .

Tilling, Thomas, "Timesharing Vacation Homes," Parent, December 1981, p. 46-49.

The Timesharing Encyclopedia, 1979 ed., S.v. "Maintenance and Operation," vol. 7 .

The Timesharing Encyclopedia, 1979 ed., S.v. "Financing," vol. 5 .

The Timesharing Encyclopedia, 1979 ed., S.V. "Regulation of Resort Timesharing," vol. 2 .

"Timesharing: New Way to Buy a Vacation Home," Changing Times, January 1978, p. 40-42.

"Timesharing: Wave of Future?" The Miami Herald, July 15, 1979, p. 19.

Trowbridge, Keith W., "A Slice of Time," Real Estate Today, March $1980, p .36-42$.

Trowbridge, Keith w., Resort Timesharing, New York, Simon and Schuster, 1981 .

Vacation Planner and Directory, Miami, Florida, Interval International, 1981-1982.

"Vacation Timesharing ... Catching On," sunset, October 1980, p. $62-66$. 